San Jose State University

SJSU ScholarWorks

Master's Theses

Master's Theses and Graduate Research

Summer 2014

\title{
The Footprints of Saharan Air Layer and Lightning on the Formation of Tropical Depressions over the Eastern Atlantic Ocean
}

Diana Caroly Centeno

San Jose State University

Follow this and additional works at: https://scholarworks.sjsu.edu/etd_theses

\section{Recommended Citation}

Centeno, Diana Caroly, "The Footprints of Saharan Air Layer and Lightning on the Formation of Tropical Depressions over the Eastern Atlantic Ocean" (2014). Master's Theses. 4456.

DOI: https://doi.org/10.31979/etd.cq5z-6zek

https://scholarworks.sjsu.edu/etd_theses/4456

This Thesis is brought to you for free and open access by the Master's Theses and Graduate Research at SJSU ScholarWorks. It has been accepted for inclusion in Master's Theses by an authorized administrator of SJSU ScholarWorks. For more information, please contact scholarworks@sjsu.edu. 


\title{
THE FOOTPRINTS OF SAHARAN AIR LAYER AND LIGHTNING ON THE FORMATION OF \\ TROPICAL DEPRESSIONS OVER THE EASTERN ATLANTIC OCEAN
}

\author{
A Thesis \\ Presented to \\ San José State University \\ In Partial Fulfillment \\ of the Requirements for the Degree \\ Master of Science
}

The Faculty of the Department of Meteorology and Climate Science

by

Diana C. Centeno Delgado

August 2014 
(C) 2014

Diana C. Centeno Delgado ALL RIGHTS RESERVED 
The Designated Thesis Committee Approves the Thesis Titled

THE FOOTPRINTS OF SAHARAN AIR LAYER AND LIGHTNING ON THE FORMATION OF TROPICAL DEPRESSIONS OVER THE EASTERN ATLANTIC OCEAN

by

Diana C. Centeno Delgado

APPROVED FOR THE DEPARTMENT OF METEOROLOGY AND CLIMATE SCIENCE

SAN JOSÉ STATE UNIVERSITY

August 2014

Dr. Sen Chiao

Department of Meteorology and Climate Science

Dr. Craig Clements

Department of Meteorology and Climate Science

Dr. Duane Stevens

Department of Meteorology, University of Hawaii 


\section{ABSTRACT \\ THE FOOTPRINTS OF SAHARAN AIR LAYER AND LIGHTNING ON THE FORMATION OF \\ TROPICAL DEPRESSIONS OVER THE EASTERN ATLANTIC OCEAN \\ by Diana C. Centeno Delgado}

In this study, the results of an observational analysis and a numerical analysis on the role of the Saharan Air Layer during tropical cyclogenesis (TC-genesis) are described. The observational analysis investigates the interaction of dust particles and lightning during the genesis stage of two developed cases (Hurricanes Helene 2006 and Julia 2010). The Weather Research and Forecasting (WRF) and WRF-Chemistry models were used to include and monitor the aerosols and chemical processes that affect TCgenesis. The numerical modeling involved two developed cases (Hurricanes Helene 2006 and Julia 2010) and two non-developed cases (Non-Developed 2011 and Non-Developed 2012). The Aerosol Optical Depth (AOD) and lightning analysis for Hurricane Helene 2006 demonstrated the time-lag connection through their positive contribution to TCgenesis. The observational analyses supported the fact that both systems developed under either strong or weak dust conditions. From the two cases, the location of strong versus weak dust outbreaks in association with lightning was essential interactions that impacted TC-genesis. Furthermore, including dust particles, chemical processes, and aerosol feedback in the simulations with WRF-CHEM provides results closer to observations than regular WRF. The model advantageously shows the location of the dust particles inside of the tropical system. Overall, the results from this study suggest that the SAL is not a determining factor that affects the formation of tropical cyclones. 


\section{ACKNOWLEDGEMENTS}

It has been an honor to have the help and support of an amazing group of individuals in this adventure of completing my thesis. First, I would like to thank my advisor and mentor, Dr. Sen Chiao. I owe him a great deal. It is very hard to summarize all the admiration and respect that I have for Dr. Chiao. Under his advising, I was able to develop many skills as a researcher and as an individual. Dr. Chiao was a constant source of encouragement, always providing feedback to help me improve at each stage of this journey. I also thank the other members of my committee: Dr. Craig Clements and Dr. Duane Stevens. Your help, feedback and support are greatly appreciated.

I would like to thank everyone at the Meteorology and Climate Science Department for their support and for making me feel at home in these last three years. This work would not have been completed without the emotional support, advice and encouragement of Areana Flores, Arthur J. Eiserloh, and Philip Martin. There are many others that I would love to mention if I had space, but they know who they are.

Finally, I would like to thank my family: my blood-related family from Puerto Rico and my adoptive family from California. This journey could not have been started and finished without the love and support from my mom Freyda, my sister Jesa, and her husband Luis D., my stepfather José, (I know you are looking at me proudly from a better place), my second mom Rhonda, my second stepfather John, and my awesome boyfriend Trent. 


\section{TABLE OF CONTENTS}

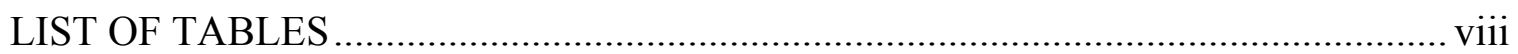

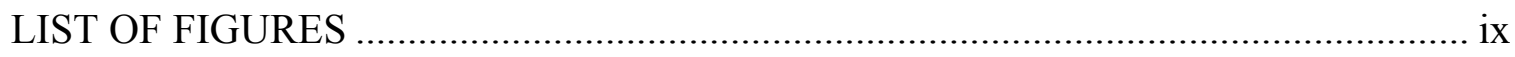

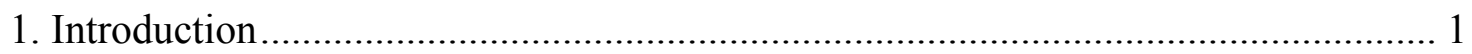

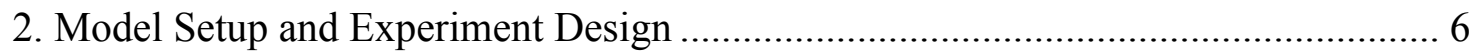

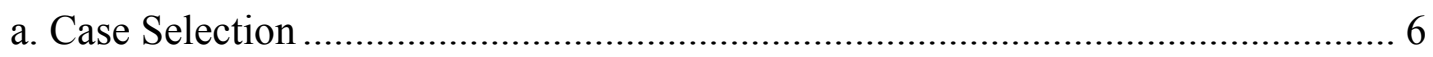

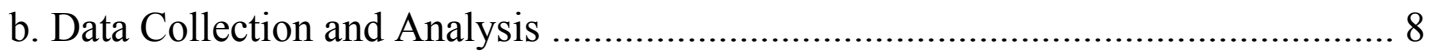

c. The Weather Research and Forecasting (WRF) and WRF- Chemistry (WRF-

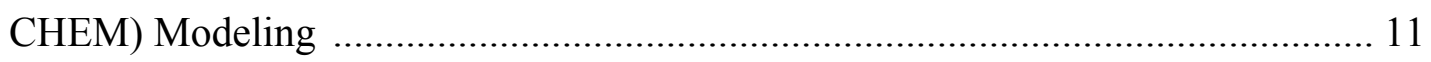

3. Observations: Evolution of SAL Outbreaks and TC-genesis .............................. 12

a. The Formation of Hurricane Helene (2006) ................................................. 12

b. The Formation of Hurricane Julia (2010) ....................................................... 14

c. AOD and SAL comparisons for Helene (2006) and Julia (2010) ...................... 17

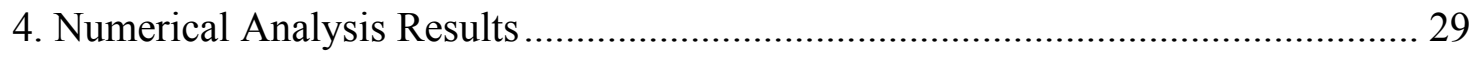

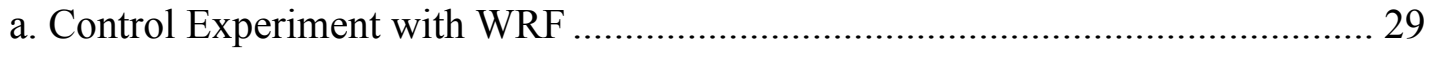

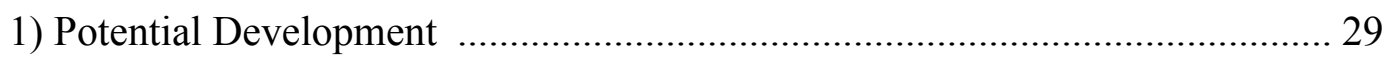

b. Dust Sensitivity Experiment with WRF-CHEM........................................... 32

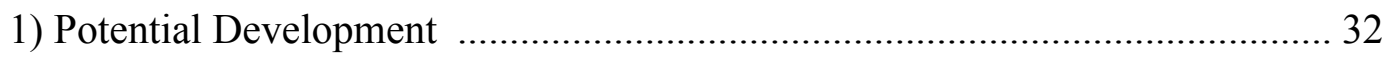

2) Vertical Distribution of Moisture ..................................................... 35

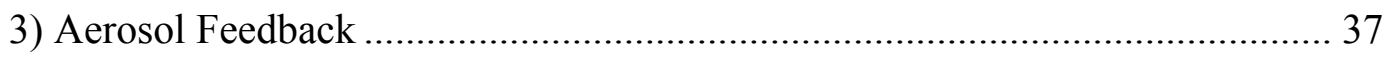

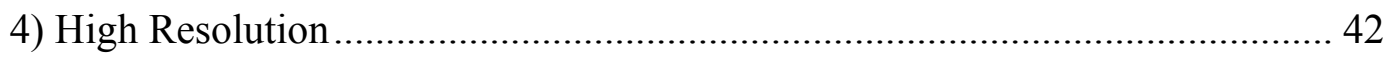

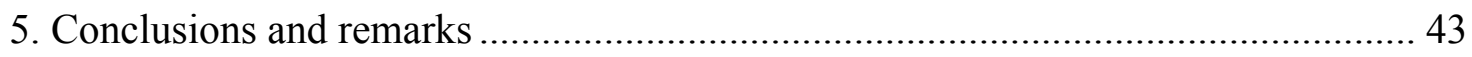




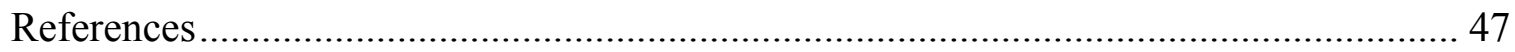

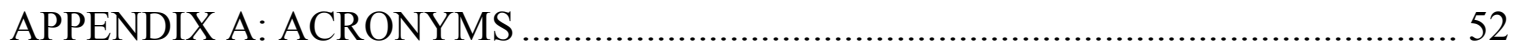




\section{LIST OF TABLES}

TABLE 1: Wind shear and RH analyses using soundings for Helene (2006).................. 14

TABLE 2: Wind shear and RH analyses using soundings for Julia (2010) ..................... 16

TABLE 3: Total amounts of the moisture variables from the cross sections designated

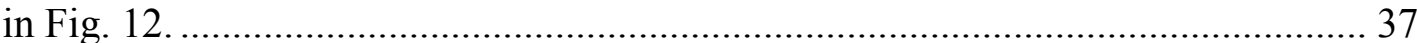




\section{LIST OF FIGURES}

FIG. 1: Meteosat-8 SAL Product Analysis of tropical cyclones TD 8, TD 12, NonDeveloped 2011, and Non-Developed 2012 .................................................. 8

FIG. 2: Vertical profiles of RH, WS, and WD for Helene 2006. ................................. 13

FIG. 3: Vertical profiles of RH, WS, and WD for Julia 2010 ................................... 15

FIG. 4: NCEP day-mean $500 \mathrm{hPa}$ geopotential height data valid for 11 September

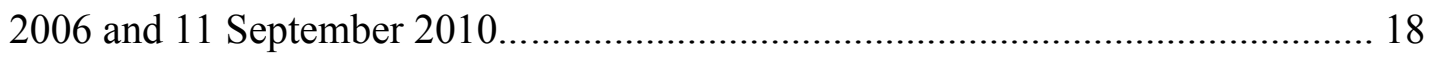

FIG. 5: CALIPSO total attenuated backscatter and vertical feature mask valid at 12

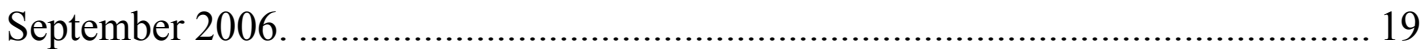

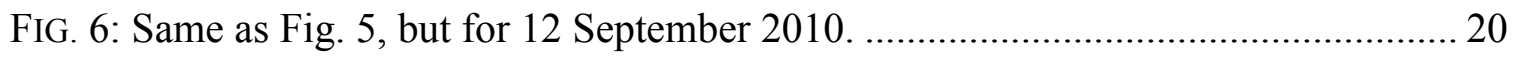

FIG. 7: NCEP Reanalysis U-Wind and PW for Helene 2006 and Julia 2010 ................. 22

FIG. 8: Daily total accumulated ATD lightning strokes from September 11 to 13 for

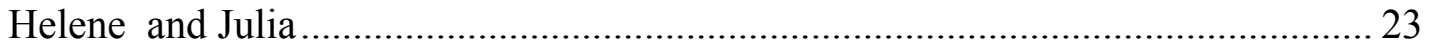

FIG. 9: MODIS AOD for September 2006 and September 2010................................. 26

FIG. 10: Comparison of ATD lightning strokes and AOD of TD 8 and TD 12 .............. 27

FIG. 10: Comparison of ATD lightning strokes and AOD of TD 8 and TD 12

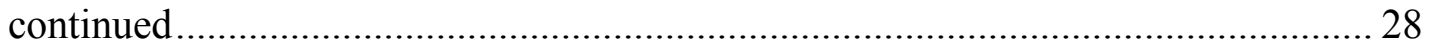

FIG. 11: WRF $850 \mathrm{hPa}$ relative vorticity and wind vectors for Helene 2006, Julia

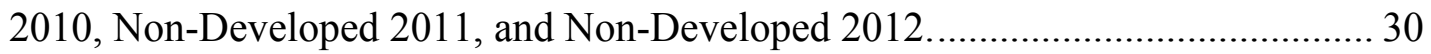

FIG. 12: WRF radar reflectivity for Helene 2006, Julia 2010, Non-Developed 2011, and Non-Developed 2012. 
FIG. 13: WRF-CHEM $850 \mathrm{hPa}$ relative vorticity and wind vectors for Helene 2006, Julia 2010, Non-Developed 2011, and Non-Developed 2012............................. 33

FIG. 14: WRF-CHEM radar reflectivity for Helene 2006, Julia 2010, Non-Developed

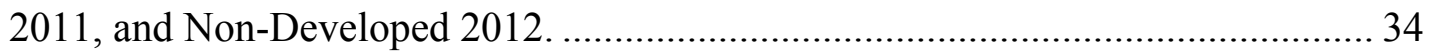

FIG. 15: WRF and WRF-CHEM moisture profiles for Helene 2006 and Julia 2010 ....... 36

FIG. 16: Simulated downward shortwave flux at ground surface ................................ 38

FIG. 17: Simulated Potential Temperature (K) and sounding temperature profile ........... 39

FIG. 18: Difference between WRF-CHEM simulations with and without aerosol

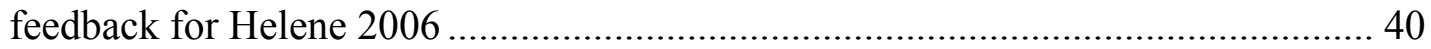

FIG. 19: Comparison of the four different simulated scenarios of Helene 2006 ............. 43 


\section{Introduction}

Tropical cyclogenesis (TC-genesis) and rapid intensification remain key areas of scientific research that have important implications for the operational community. While pre-existing disturbances [e.g., African Easterly Waves (AEWs)] are often precursors to tropical cyclone formation, the large-scale environment (i.e., shear, moisture, and potential vorticity) also plays an important role in TC-genesis. Equally important are the internal changes in the storm that may be affected by the Saharan Air Layer (SAL) during the genesis stage. However, the overall understanding of the SAL in association with dust particles on TC formation processes is still deficient or inconclusive (Zhang et al. 2007; Tao et al. 2007; Jenkins and Pratt 2008; Jenkins et al. 2008; Braun 2010a).

The SAL is a dry layer that extends up to approximately $500 \mathrm{hPa}(\sim 5500 \mathrm{~m})$ over Africa in the summer months (Prospero and Carlson 1972; Carlson and Prospero 1972). This elevated layer of Saharan air and mineral dust can be transported to other regions beyond the West African area. For example, it can be found in the North Atlantic, western Caribbean Sea, and Gulf of Mexico (Dunion and Velden 2004), as well as in the western U.S. (Creamean et al. 2013). Therefore, its impact is of great importance to a large number of scientific and civil communities. For instance, the dust particles can have impacts on ocean (e.g., sea surface temperature changes), air quality (e.g., respiratory aspects), as well as on weather events (e.g., formation of precipitation in tropical cyclone genesis, Lau et al. 2007a; Prospero and Mayol-Bracero 2013). During the past decade various hypothesis and theories have been developed over both the 
positive and negative impact of the SAL on AEWs and on TC formation (e.g. Zipser et al. 2009). Dunion and Velden (2004) proposed that the SAL can inhibit the growth of systems by introducing dry, stable air and enhancing vertical wind shear through the African Easterly Jet (AEJ). Along similar conclusions, Rosenfeld et al. (2001) suggested that the SAL could reduce precipitation efficiency. These dust particles, acting as cloud condensation nuclei $(\mathrm{CCN})$, may cause changes in the formation and distribution of precipitation, redistribution of latent heat (Rosenfeld et al. 2008; Rosenfeld et al. 2012), and they could impact the intensity of the storm (e.g., Braun et al. 2013). On the other hand, Jenkins et al. (2008) concluded that aerosol-cloud interactions invigorate convective rain bands via an entrainment of dust particles at altitudes greater than the 825 hPa level due to the strong midlevel jet associated with the SAL. Khain et al. (2005) also suggested that microphysics could enhance convective intensity in the systems. These findings are significant since AEWs have been found to be a clear precursor of the major hurricanes that form in the Atlantic (Karyampudi and Carlson 1988; Karyampudi and Pierce 2002) affecting habitants of the Caribbean, Mexico, part of Central America, and the east and southeast United States.

Using the National Aeronautics and Space Administration (NASA) GOES-5 Global Forecasting System, Reale et al. (2011) concluded that the net impact of the interactive aerosol, associated with a strong Saharan dust outbreak, increased temperatures at the dust level while decreasing temperatures at near-surface levels, likely creating a net negative impact on the convective development (i.e., less surface heating and a more stable temperature profile above the surface). They further demonstrated that 
forecasts in which interactive aerosols are included depict an AEJ at a slightly higher elevation that is slightly displaced northward with respect to forecasts in which aerosols are not included. Sun et al. (2009) suggested that dry air entrainment and the enhanced vertical wind shear might have direct roles in leading to the TC suppression. In contrast, a recent case study by Sippel et al. (2011) concluded that even though the SAL may have slowed intensification during the pre-tropical depression (TD) to TD stages of Tropical Storm Debby (2006), it was not likely responsible for Debby's dissipation. Previous studies (Evan et al. 2006; Zhang et al. 2007; Evan et al. 2008; Wong et al. 2008) also suggest a statistically significant inverse relationship between the amount of dust covering the region of development and TC activity in the North Atlantic. Additionally, high amounts of dust in the North Atlantic may decrease temperatures causing a decrease in cyclone activity (Lau and Kim 2007a, b and c).

Although many observational and modeling studies have investigated the effect of the SAL dust particles on precipitation, TC activity, and sea surface temperatures (SSTs), not many have analyzed the microphysics involved in the TC-genesis process. Nonetheless, it is still not clear how these changes in microphysics in association with SAL would affect TC-genesis. The uncertainty of the connection between AEWs, the SAL, and TC-genesis motivated NASA to expand research into the Eastern Atlantic with the NASA-AMMA (NAMMA) field project (Zipser et al. 2009). The campaign successfully collected various datasets from AEWs and the SAL for developed and nondeveloped TCs. As a combined effort from NASA, the National Oceanic and Atmospheric Administration (NOAA), and the National Science Foundation (NSF), three 
field campaigns were conducted during the 2010 hurricane season to investigate TCgenesis and the intensification of each system in the Caribbean and western/central North Atlantic. From these campaigns, PREDICT (Pre-Depression Investigation of Cloudsystems in the Tropics) focused on the study of the genesis pertaining to insipient tropical disturbances. However, the PREDICT campaign's domain focused on the West Atlantic and the Caribbean, which is a region out of this present study's domain. The NOAA's Intensity Forecasting Experiment (IFEX) missions were conducted in the Gulf of Mexico, Caribbean, and western North Atlantic in 2010, which are also outside of this study's domain. The NASA Genesis and Rapid Intensification Processes (GRIP) experiment, on the other hand, focused on the internal structure and environment as each system intensified (Braun et al. 2012) and included measurements obtained from locations inside the domain of interest for this work.

This study utilized the datasets collected during the NAMMA and GRIP field experiments. Even though none of the missions conducted during the GRIP experiment were focused in the eastern north Atlantic, radiosondes were launched from the Cape Verde Islands during the experiment. Therefore, data from both the NAMMA and GRIP field experiments were incorporated in this study. This work's hypotheses are

1. Time-lag response exists between the observed high values of Aerosol Optical Depth (AOD) in association with the SAL and the observed high amounts of lightning strokes over the eastern tropical Atlantic Ocean.

2. Intrusion of dust particles associated with SAL during the genesis stage of TCs, invigorates the system by increasing the number of cloud droplets. As a result, the 
entire TC genesis processes may be delayed or diminished.

The high amount of lightning strokes is suspected to be due to the increase in dust particles acting as cloud condensation nuclei (CCN; Twohy et al. 2009 and Yuan et al. 2011), which enhance the possibility of moist convective overturning with vertical circulation within the inner-core of an MCS over West Africa and the adjacent eastern tropical Atlantic Ocean. Subsequently, more precipitation would produce more latent heat that converts into sensible heat. One of the focuses of this study is to analyze processes that drive lightning formation (dust particles as $\mathrm{CCN}$ ) that are not the thermodynamically driven processes commonly analyzed. Using measurements collected from field experiments, we studied the extent to which the Saharan dust in association with $\mathrm{CCN}$ may affect TC-genesis processes. Furthermore, we evaluated the differences between the Weather Research and Forecasting - Advanced Research WRF (WRFARW) and the WRF-Chemistry (WRF-CHEM) models, as well as analyzed the sensitivity of WRF-CHEM to model the effects from the Saharan dust.

The WRF model has been successfully used for the study of dust-radiation effects of dust outbreaks from the West coast of Africa (Chen et al. 2010). Although, in their work, Chen et al. (2010) found that even if the model was successful at simulating the dusty conditions by including a tracer, it still encountered discrepancies in the temperatures possibly caused by inaccurate optical properties. The WRF-Chem model on the other hand, already incorporates a chemistry module that simulates the emission, transport, and chemical transformation of gases and aerosols, which could reduce the inaccuracies. The addition of the chemical aspect in the simulations has proven effective 
in the study of airborne particle matter (health risk, Zhang et al. 2013), dust-radiation effects and pre-monsoon dust storm events (Kumar et al. 2013), cold pools (haboobs) and dust emissions over the Sahara (Carvazos-Guerra and Todd 2012), and the uncertainty from size parameterization of the dust bins used in the WRF-Chem model to simulate radiative forcing (Zhao et al. 2013).

To advance the understanding of the effects of dust particles on the formation or suppression of tropical cyclones, in this research in situ and remote sensing measurements were analyzed to represent the West Africa and Eastern Atlantic atmospheric circulation, vertical moisture distribution, and convection during two TCgenesis events in 2006 and 2010, respectively. Key features for consideration include: the distribution of lightning strokes, AOD, moisture profiles, African easterly jets, and the location of strong versus weak SAL outbreaks. Additionally, numerical analyses of four different TC genesis related events are conducted to study the genesis as well as early evolution of tropical systems. In section 2 the model setup and the experimental design are outlined. Section 3 depicts the dust outbreak and TC-genesis of the two events as well as cloud properties comparisons. The discussion of the numerical analyses is in Section 4 and conclusions are given in Section 5.

\section{Model Setup and Experiment Design}

\section{a. Case Selection}

The cases were selected to represent different environmental (background) conditions, strong dust outbreak or weak dust outbreak, and to represent different tropical 
cyclogenesis outcomes, developed or non-developed. Imagery from the 12.0 and $10.8 \mathrm{~m}$ infrared channels on the Meteosat satellite was obtained to observe the position and movement of the SAL dust particles (Fig. 1). Case study \#1, Helene (2006), developed from AEW \#7 and was declared a tropical depression (TD) \#8 on 1200 UTC 12 September 2006. As shown in Fig. 1a, TD 8 developed under a moderate dust outbreak covering the north and northwestern parts of this system.

Case study \#2, Hurricane Julia (2010), was declared TD \#12 on 0600 UTC 12 September 2010. Julia formed after a higher dust outbreak, but by the time of its formation most of the dust particles had scattered. Still, the north and northwestern regions of Julia were in contact with small clusters of dust particles (Fig. 1b).

Case \#3, a non-developed event in 2011, initiated its transition from the African continent towards the Atlantic basin on 0000 UTC 2 September 2011. The background environment was characterized by scattered dust particles towards the northern region of the cloud cluster (Fig. 1c). Even though it showed signs of early stage development along the coast of Senegal, it started to dissipate 12 hours later until the cloud structure completely broke down by 0000 UTC 4 September 2011.

Case \#4, another non-developed event in 2012, initiated its transition from the African continent towards the Atlantic basin on 2100 UTC 30 August 2012 under a strong dust outbreak located towards the north, northwest of its cloud cluster (Fig. 1d). Similarly to Case \#3, this event showed signs of early stage development. However, the cloud cluster weakened until it completely dissipated by 1200 UTC 01 September 2012. 


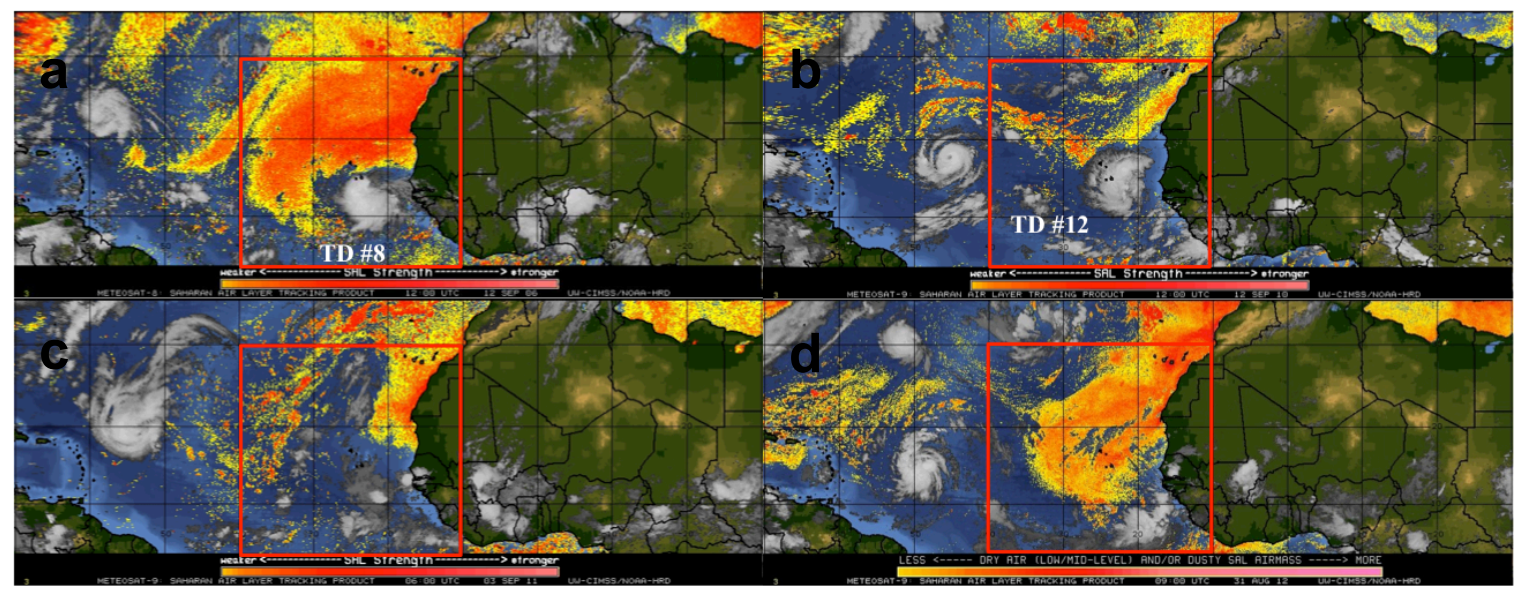

Figure 1: Meteosat-8 SAL Product Analysis of tropical cyclones (a) TD 8 (Helene) on 12 September 2006 at 12 UTC, (b) TD 12 (Julia) on 12 September 2010 at 12 UTC, (c) Case \#3 Non-Developed 2011, and (d) Case \#4 Non-Developed 2012 (available at the University of Wisconsin - CIMSS http://tropic.ssec.wisc.edu/tropic.php). The red box denoted the analysis region (Note: Some of the analyzed domain is cutoff in the lower boxes in these images.). Both developed systems can be observed inside of the target area in each figure, TD8 at the southern region of the box and TD 12 at the center region of the box.

\section{b. Data Collection and Analysis}

The uncertainty related to TC-genesis of disturbances that are under the influence of the SAL still serve as an inspiration to target the dry and dusty air of the environment. To better visualize these characteristics Hurricane Helene (2006) and Hurricane Julia (2010) were examined since both systems obtained TD status around the same time frame and spatial location (12 September 2006 and 12 September 2010, respectively).

Therefore, key similarities and differences in their environment would be feasible to identify. Another important factor that affected the decision in selecting these two systems was that the SAL is most active from mid June to late July (Carlson and Prospero 1972; Dunion and Marron 2008; Dunion 2011). Therefore, cases chosen from different 
months for comparison (e.g., July against September) could be affected differently by the SAL, and would alter the values of different parameters and the purpose of this study. In terms of location, the Cape Verde Islands provide useful insight as to the conditions north of the formation of the two systems that were near the area where the SAL outbreaks took place.

Data of different meteorological parameters (e.g., temperature, relative humidity, wind speed, wind direction) from in situ measurements and remote sensing were used for reconstructing the synoptic and mesoscale conditions (i.e., background environment). Hovmoller diagrams using the National Centers for Environmental Prediction (NCEP) reanalysis data $(2.5 \times 2.5$ degree resolution) were applied to depict the traverse of AEW leaving the West African coast, as well as to identify any influence from the AEJ. Vertical profiles of temperature, moisture, and wind shear between $200 \mathrm{hPa}$ and $850 \mathrm{hPa}$ were created using radiosondes launched from Praia, Cape Verde (NAMMA) and Saint Vincent, Cape Verde (GRIP) before, during, and after the NOAA National Hurricane Center named the storm.

The vertical shear was calculated using the difference between winds averaged in the 300-200 hPa layer and those averaged in the 850-700 hPa layer (Gallina 2002; DeMaria et al. 2005; Rhome et al. 2006). Meteosat-SAL imagery from the University of Wisconsin-CIMSS was used to observe the position and movement of the SAL outbreaks. These products are derived using the differences of the 12.0 and $10.7 \mu \mathrm{m}$ infrared channels on the GOES satellite and 12.0 and $10.8 \mu \mathrm{m}$ infrared channels on the Meteosat satellite (Dunion and Velden 2004). The algorithm is sensitive to the presence 
of dry and/or dusty air in the lower to middle levels $(\sim 850-600 \mathrm{hPa})$ of the atmosphere (Information provided by the University of Wisconsin-CIMSS Tropical Cyclones Web site at http://tropic.ssec.wisc.edu/misc/sal/info.sal.m8split.html). The analysis area (i.e., 10-40 W, 0-30E) was divided into nine $10 \times 10$ degree boxes as shown in Fig. 1.

Daytime AOD $550 \mathrm{~nm}$ fine mode fraction data from the Moderate Resolution Imaging Spectroradiometer (MODIS) aboard NASA's Aqua and Terra satellites were collected from the MODIS Online Visualization and Analysis System (MOVAS) to analyze the amount of dust particles that could have influenced tropical storms (Acker and Leptoukh 2007). Additionally, aerosol imagery corresponding to the day of formation of both TDs (12 September 2006 and 12 September 2010) was obtained from the Cloud-Aerosol Lidar and Infrared Pathfinder Satellite Observations (CALIPSO) satellite from the Atmospheric Science Data Center (ASDC) at the NASA Langley Research Center.

The total attenuated backscatter and the vertical feature mask images provided a better understanding of the aerosol location and type, respectively, at the time of the formation of the tropical storms. The Arrival Time Difference (ATD) lightning strokes data for the month of September were obtained for both 2006 and 2010 years in order to find connections between the amount of the dust particles and the amount of lightning. The ATD system detects mainly cloud to ground lightning. More details of the system, including estimated location errors and updates, can be found in Lee (1990) and Gaffard et al. (2008). Lastly, comparisons between ATD lightning strokes and AOD among the nine boxes (analysis area) were performed. 
c. The Weather Research and Forecasting (WRF) and WRF-Chemistry (WRF-CHEM) Modeling

The WRF-ARW model version 3.4 (Skamarock et al. 2008) and the WRF-Chem model version 3.4.1 (Grell et al. 2005) were employed for the four case studies, and the WRF-Chem version 3.5.1 was employed for the simulations with aerosol feedback. Both models were used to evaluate the differences in the environmental conditions prior, during, and post TC genesis. The WRF Pre-Processing System (WPS) version 3.4 was used to provide data as input for the real case programs. The initial and time-dependent lateral boundary conditions are supplied from NCEP Global Forecast System (GFS) 3hourly global analysis at $0.5^{\circ}$ horizontal resolution. The configuration of the models was the same, except for the chemistry module used in WRF-CHEM. The horizontal grid spacing selected was $15 \mathrm{~km}$ with 61 vertical levels. The microphysics scheme used was the WRF Single-Moment 5-class (WSM5) scheme (Hong et al. 2004). Other physics schemes used include the Yonsei University (YSU) scheme for the planetary boundary layer (Hong et al. 2006), the NOAH scheme for the land surface physics (Ek et al. 2003), the Goddard scheme for the shortwave radiation physics (based on Chou and Suarez 1994), the Rapid Radiative Transfer Model (RRTM) scheme for the longwave radiation physics (Mlawer et al. 1997), and the Goddard Chemistry Aerosol Radiation Transport (GOCART, Ginoux et al. 2001) simple aerosol scheme (no ozone chemistry) for the chemistry option in WRF-CHEM.

The primary interest in using the GOCART aerosol scheme is that the model can simulate dust concentration and meteorological fields over West Africa and the adjacent 
eastern tropical Atlantic Ocean (e.g., Drame et al. 2011). It simulates the emissions as a function of surface wind speed, surface erodibility, and surface wetness. The WRFCHEM model also incorporates an emissions-input data to add (i.e., PREP CHEM SOURCES) anthropogenic emissions and GOCART background information to the simulations. The WRF-CHEM model version 3.4.1 did not offer the option of aerosol feedback with the GOCART scheme option and the preciously mentioned configuration. Therefore, the analysis of the effects of the aerosol feedback in the simulations was conducted using WRF- CHEM version 3.5.1.

\section{Observations: Evolution of SAL Outbreaks and TC-genesis}

In this section we describe the synoptic and mesoscale conditions for both cases around the Cape Verde Islands on the day prior the formation, during the formation, and after the TD was named.

\section{a. The Formation of Hurricane Helene (2006)}

Helene (2006) developed from AEW \#7 and was declared as TD \#8 on 12 September 2006 at $1200 \mathrm{UTC}$ at latitude of $11.9^{\circ} \mathrm{N}$ and a longitude of $22^{\circ} \mathrm{W}$ with a central pressure $1007 \mathrm{hPa}$ and maximum sustained winds of $12.9 \mathrm{~m} \mathrm{~s}^{-1}$. The MeteosatSAL analysis suggested that the system developed under a strong dust outbreak covering the north and northwestern areas of the system (Fig. 1a). Relative humidity (RH) analyses for $850 \mathrm{hPa}$ and $700 \mathrm{hPa}$ from radiosondes launched at the Cape Verde Islands (Fig. 2) illustrated the changes in humidity from the day prior to TC-genesis, during TCgenesis, and after. At $850 \mathrm{hPa}$ (Fig. 2a), an increase can be seen starting at $44.5 \%$ (prior 

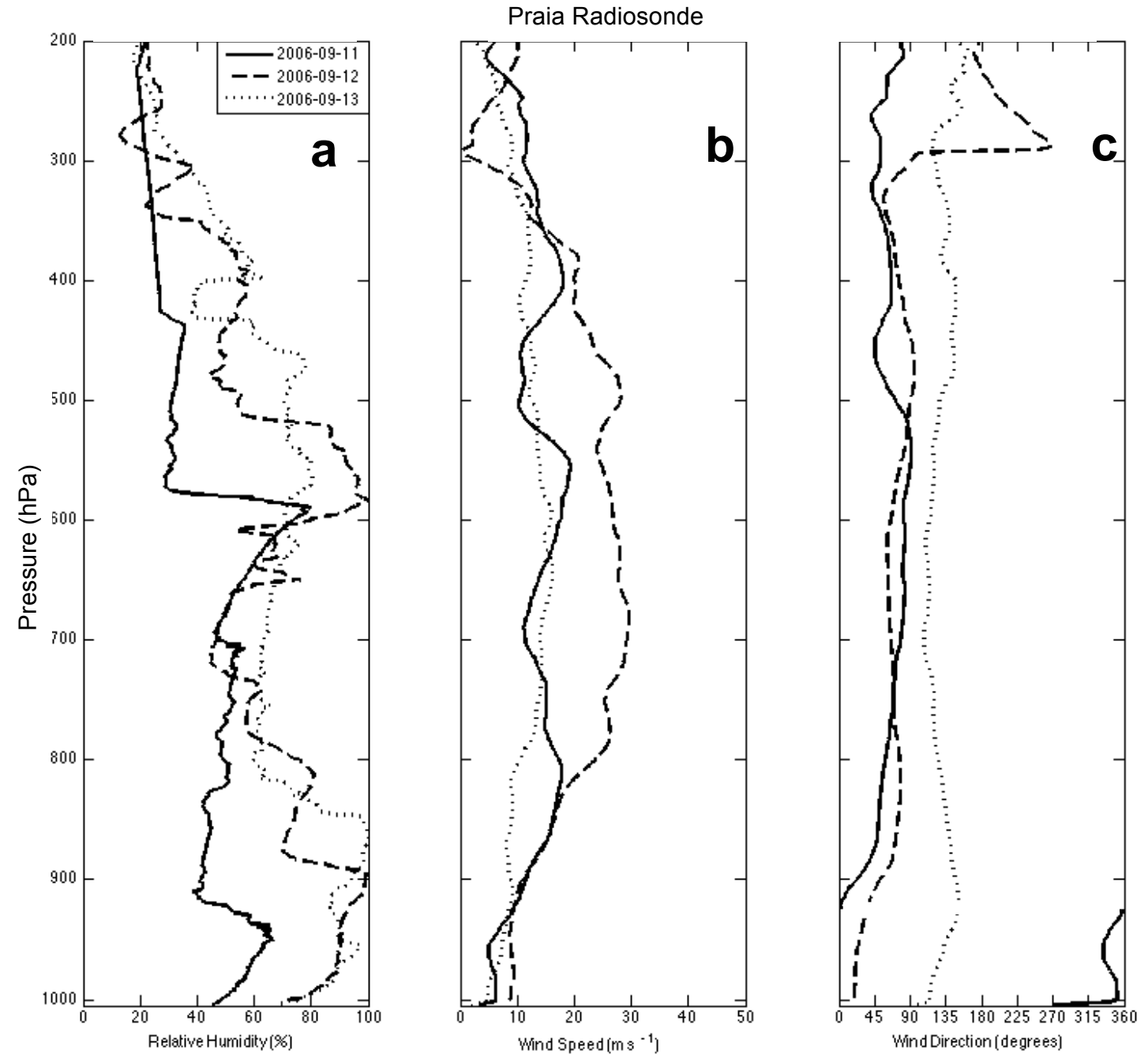

Figure 2: Vertical profiles of (a) relative humidity, (b) wind speed, and (c) wind direction before, during, and after Helene (2006) named by NHC.

to TC-genesis; 11 September 2006), to 74.1\% (day of TC-genesis, 12 September 2006), and then to $98 \%$ (after TC-genesis, 13 September 2006). However, this daily increase was not observed at $700 \mathrm{hPa}$ (Table 1). The RH values at $700 \mathrm{hPa}$ decreased from $48.5 \%$ to $47.1 \%$, and then increased to $63.0 \%$ during each of the three stages, respectively.

Similar conditions were also observed from the mixing ratio profile (not shown). Low values of vertical wind shear existed from the day prior to TC-genesis until the day of 
TC-genesis (Table 1 and Fig. $2 \mathrm{~b}$ and 2c). Therefore, $6.6 \mathrm{~m} \mathrm{~s}^{-1}$ provided a favorable condition for the system to develop. There was a sharp increase in the wind shear on the day of formation of the system to $18.9 \mathrm{~m} \mathrm{~s}^{-1}$ suggesting that the sounding went through the system, followed by a significant decrease on the day post-formation $\left(5.5 \mathrm{~m} \mathrm{~s}^{-1}\right)$. Overall, the existing SAL did not inhibit the development of TD 8.

Table 1: Wind shear and RH analyses using soundings for Helene (2006)

\begin{tabular}{l|lll}
\hline \hline & $\begin{array}{l}\text { Wind Shear } \\
850-200 \mathrm{hPa} \\
(\mathrm{m} / \mathrm{s})\end{array}$ & $\begin{array}{l}\text { Relative Humidity } \\
850 \mathrm{hPa}\end{array}$ & $\begin{array}{l}\text { Relative Humidity } \\
(\%)\end{array}$ \\
Date & 12.0 & 73.7 & $\mathrm{hPa}$ \\
\hline \hline $2006 / 09 / 01$ & 2.6 & 78.0 & 61.0 \\
$2006 / 09 / 02$ & 0.9 & 97.6 & 61.2 \\
$2006 / 09 / 03$ & 1.7 & 87.3 & 100.0 \\
$2006 / 09 / 04$ & 2.9 & 51.9 & 40.4 \\
$2006 / 09 / 05$ & 3.2 & 43.4 & 41.0 \\
$2006 / 09 / 06$ & 3.2 & 42.3 & 39.3 \\
$2006 / 09 / 07$ & 1.4 & 33.7 & 42.9 \\
$2006 / 09 / 08$ & 3.0 & 85.7 & 44.7 \\
$2006 / 09 / 09$ & 7.1 & 66.3 & 76.2 \\
$2006 / 09 / 10$ & 5.2 & 44.5 & 57.0 \\
$2006 / 09 / 11$ & 6.6 & 74.1 & 48.5 \\
$2006 / 09 / 12$ & 18.9 & 98.1 & 47.1 \\
$2006 / 09 / 13$ & 5.5 & 86.0 & 63.0 \\
$2006 / 09 / 14$ & 1.0 & & 51.5 \\
\hline
\end{tabular}

b. The formation of Hurricane Julia (2010)

Hurricane Julia (2010) was declared as TD\#12 on 12 September 2010 at 0600 UTC at latitude of $12.9^{\circ} \mathrm{N}$ and a longitude of $20.5^{\circ} \mathrm{W}$ with a central pressure of $1007 \mathrm{hPa}$ and maximum sustained winds of $14.9 \mathrm{~m} \mathrm{~s}^{-1}$. TD 12 formed under a weak dust outbreak, in which most of the dust particles had scattered by the time of TC-genesis. The regions north and northwest of TD 12 were in contact with small clusters of dust particles 
(Fig.1b). Relative humidity values for the $850 \mathrm{hPa}$ and $700 \mathrm{hPa}$ level show a similar behavior (Table 2 and Fig. 3), decrease in RH from the day prior to TC-genesis and then an increase in humidity in the hours leading up to the day after the system reached TD status. At the $850 \mathrm{hPa}$ level the values fluctuated from $55.3 \%$ to $35.4 \%$ and then to $87.4 \%$ between the three stages of development, respectively.
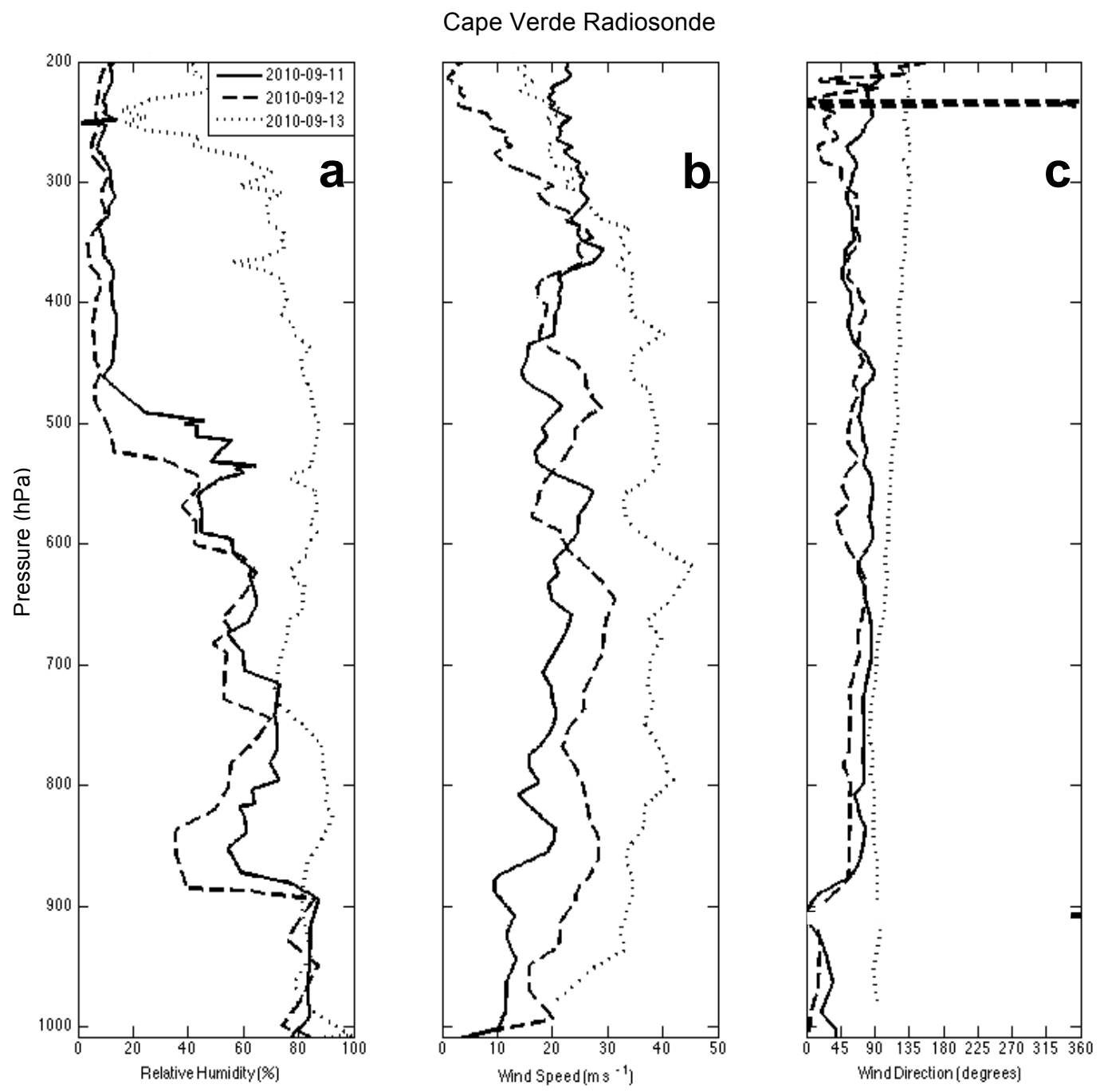

Figure 3: Vertical profiles of (a) relative humidity, (b) wind speed, and (c) wind direction before, during, and after Julia (2010) named by NHC. 
For the $700 \mathrm{hPa}$ level, values varied from $60.4 \%$ to $53.5 \%$, and then they increased to $72.8 \%$ at each developmental stage, respectively. A relative drier condition was observed from the 800 to $600 \mathrm{hPa}$ level from the radiosonde profiles prior and during the formation (Fig. 3a). This could have been the result of the system encountering an elevated (i.e., secondary) SAL layer around 4km AGL ( 600 hPa). Wind shear values increased from the $2.0 \mathrm{~m} \mathrm{~s}^{-1}$ (i.e., prior to TC-genesis) to $9.0 \mathrm{~m} \mathrm{~s}^{-1}$ (i.e., during TCgenesis), and then to $10.1 \mathrm{~m} \mathrm{~s}^{-1}$ (i.e., after TC-genesis). The low values of wind shear observed prior to TC-genesis could have been one of the factors that supported the system's formation (Table 2 and Fig $3 \mathrm{~b}$ and $3 \mathrm{c}$ ).

Table 2: Wind shear and RH analyses using soundings for Julia (2010)

\begin{tabular}{l|lll}
\hline \hline & $\begin{array}{l}\text { Wind Shear } \\
850-200 \mathrm{hPa} \\
(\mathrm{m} / \mathrm{s})\end{array}$ & $\begin{array}{l}\text { Relative Humidity } \\
850 \mathrm{hPa} \\
(\%)\end{array}$ & $\begin{array}{l}\text { Relative Humidity } \\
700 \mathrm{hPa} \\
(\%)\end{array}$ \\
\hline \hline $2010 / 09 / 01$ & 0.5 & 19.5 & 29.4 \\
$2010 / 09 / 02$ & 1.9 & 18.2 & 26.7 \\
$2010 / 09 / 03$ & 1.5 & 22.3 & 20.3 \\
$2010 / 09 / 04$ & 0.5 & 11.2 & 63.6 \\
$2010 / 09 / 05$ & 3.4 & 57.6 & 79.8 \\
$2010 / 09 / 06$ & 1.7 & 45.7 & 58.6 \\
$2010 / 09 / 07$ & 6.3 & 78.4 & 65.4 \\
$2010 / 09 / 08$ & 4.2 & 67.8 & 68.6 \\
$2010 / 09 / 09$ & $\mathrm{~N} / \mathrm{A}$ & 85.9 & 60.9 \\
$2010 / 09 / 10$ & 3.7 & 77.8 & 54.7 \\
$2010 / 09 / 11$ & 2.0 & 55.3 & 60.4 \\
$2010 / 09 / 12$ & 9.0 & 35.4 & 53.5 \\
$2010 / 09 / 13$ & 10.1 & 87.4 & 72.8 \\
$2010 / 09 / 14$ & 8.7 & 80.5 & 62.7 \\
\hline
\end{tabular}




\section{c. AOD and SAL comparisons for Helene (2006) and Julia (2010)}

Both TDs developed into hurricanes even when the intensity of dust outbreak was different for each. It can be clearly observed from the Meteosat-SAL products that there is a more significant SAL outbreak surrounding TD 8 than the amount around TD 12 (cf. Fig. 1). The NCEP Operational analysis on 11 September 2006 depicted the lowpressure system developed in association with a trough near the coastal region while a strong dust outbreak occurred (Fig. 4a). TD 12 also occurred in a similar surrounding environment on 11 September 2010 (Fig. 4b). However, the pre-existing MCS was well defined and the dust outbreak was weaker compared to what occurred during TD 8 . The sounding demonstrated that when both systems passed by the Cape Verde Islands, TD 8 retained higher values of RH than TD 12 (cf. Figs. 2 and 3). This result was further confirmed by the observational analysis from the CALIPSO $532 \mathrm{~nm}$ total attenuated backscatter (Figs. 5a and 6a). As a matter of fact, the vertical feature mask analyses from CALIPSO also demonstrated that the aerosol distributions in TD 8 were higher than TD 12 (Figs. 5b and 6b). A noteworthy feature was that TD 12 showed higher values of RH around $700 \mathrm{hPa}$ (cf. Fig. 3a), which was roughly below the altitude of the thin elevated SAL as shown in CALIPSO (Fig. 6a). Tropical depression 8 showed higher moisture content on the day of TC-genesis, although the dust-laden environment seemed to limit the vertical development of the system below $\sim 500 \mathrm{hPa}$. In contrast, conditions of less amount of dust implied that the surrounding environment was suitable for the development of TD 12, which had the moist layer reach up to $\sim 250 \mathrm{hPa}$. 

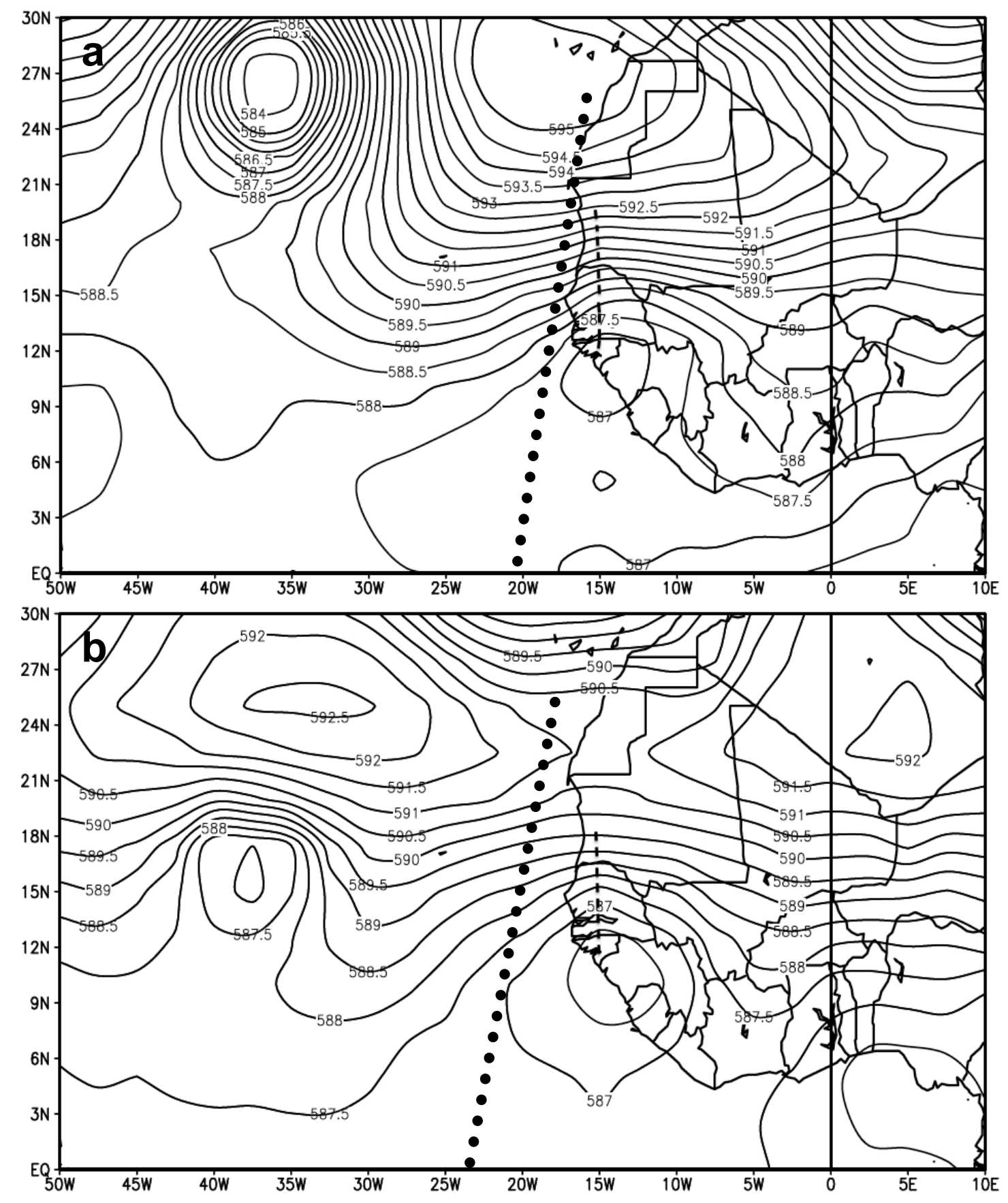

Figure 4: Day-mean 500 hPa geopotential height (dam) from NCEP operational data valid for (a) 11 September 2006 (day before the formation of TD 8 later known as Helene), and (b) 11 September 2010 (day before the formation of TD 12 later known as Julia). Dashline denotes the location of trough. Dotted line denotes the location of the vertical cut shown in Figs. 5 and 6. 

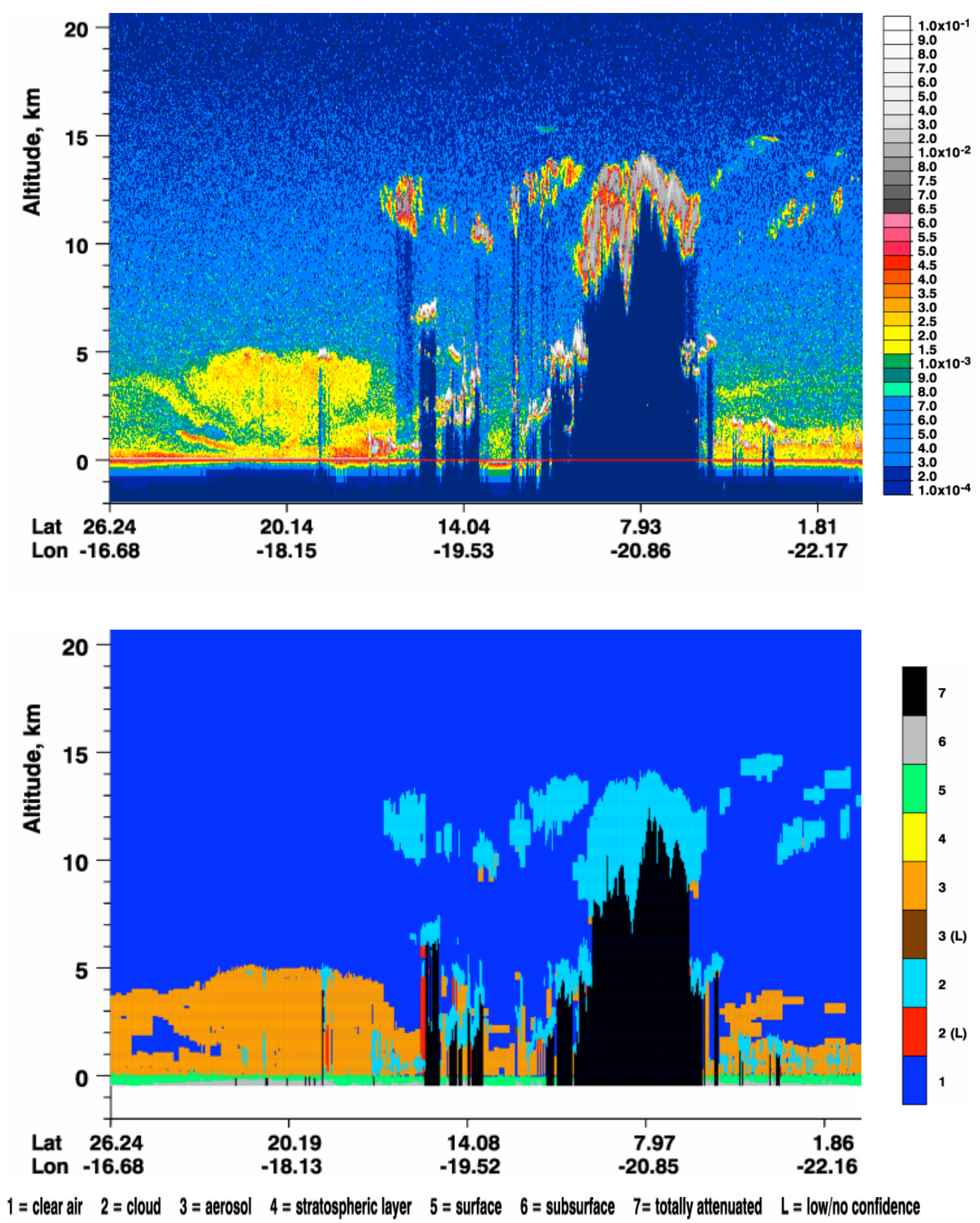

Figure 5: CALIPSO (a) $532 \mathrm{~nm}$ total attenuated backscatter $\left(\mathrm{km}^{-1} \mathrm{sr}^{-1}\right)$ and (b) vertical feature mask from the satellite valid at 12 September 2006 (day of formation of TD 8 later known as Helene). 

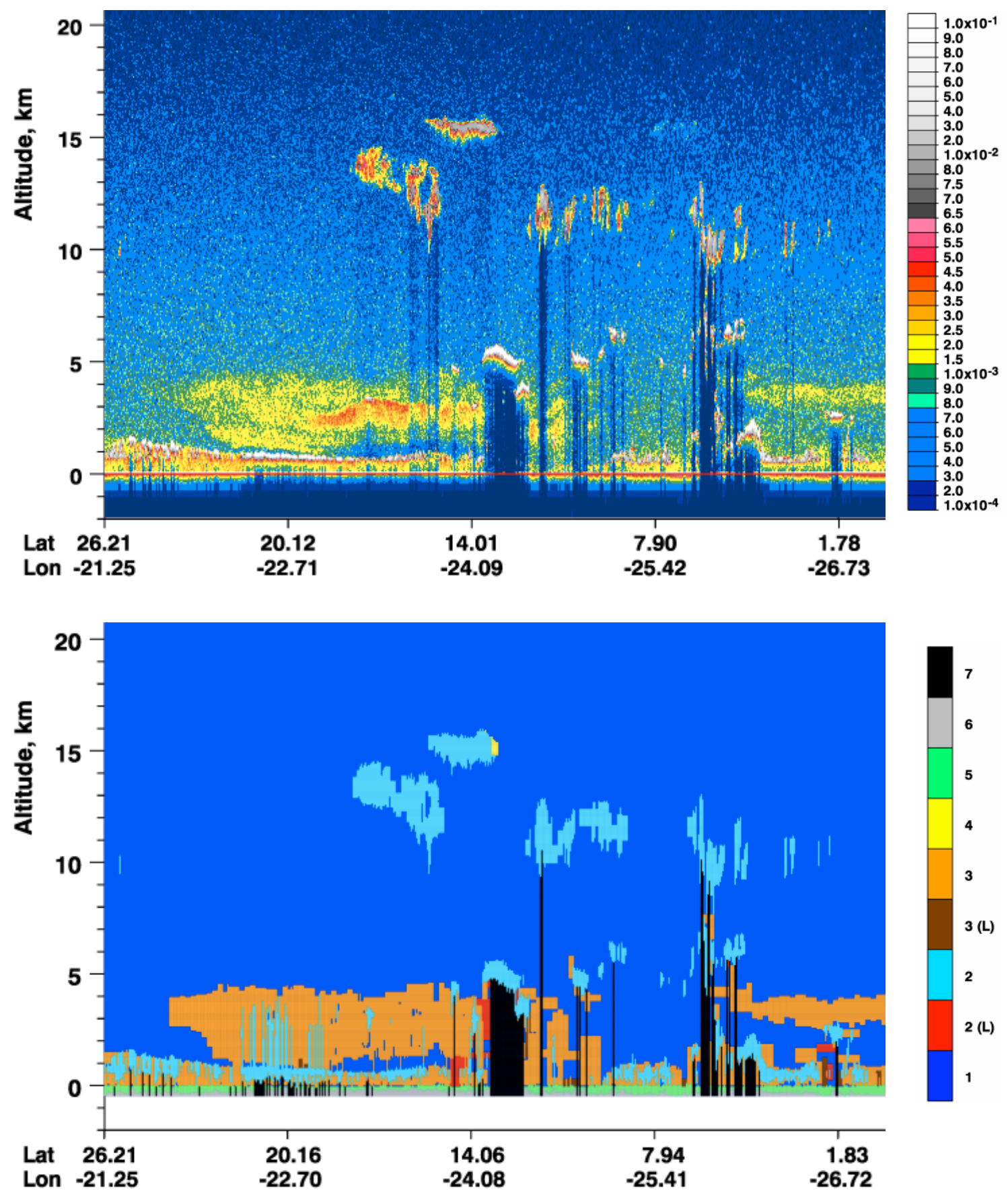

Figure 6: Same as Fig. 5, but for 12 September 2010 (day of formation of TD 12 later known as Julia). 
The progression of the AEJs and AEWs can be observed in the NCEP reanalysis data shown for mean zonal wind and precipitation in Fig. 7. Apparently, as shown in Figs. 7a and 7b, the AEJ that occurred during TD 8 was spread over a larger area (greater impact) than what occurred during TD 12 in its TC-genesis phase. Furthermore, as shown in Figs. $7 \mathrm{c}$ and $7 \mathrm{~d}$, the daily mean precipitable water $(\mathrm{PW})$ demonstrated a more organized structure in TD 12 than TD 8 during TC-genesis as it moved through the 10-40 degrees $\mathrm{W}$ longitudinal domain. These results suggest that a stronger AEJ contributed to a stronger dust outbreak (less PW) during the formation of TD 8 (e.g., Fig.7). On the other hand, the low vertical wind shear and the weaker dust outbreak (more PW) seemed to have helped create the favorable conditions for the development of TD 12. The firstorder comparison of lightning strokes before, during, and after TC-genesis of the two cases is shown in Fig. 8. It can be seen that the distributions of lightning strokes of the two systems were quite different. Although a stronger dust outbreak occurred one day prior to TC-genesis associated with TD 8 (i.e., 11 September 2010), most of the lightning strokes were recorded on September 12 and 13. In contrast to TD 8, the majority of lightning strokes associated to TD 12 were around the coastal region. Although Yuan et al. (2011) stated that a $\sim 60 \%$ increase in aerosol loading leads to more than $150 \%$ increase in lightning flashes, the results of TD 8 suggested a relationship between dust and lightning that demonstrated a time-lag correlation. 

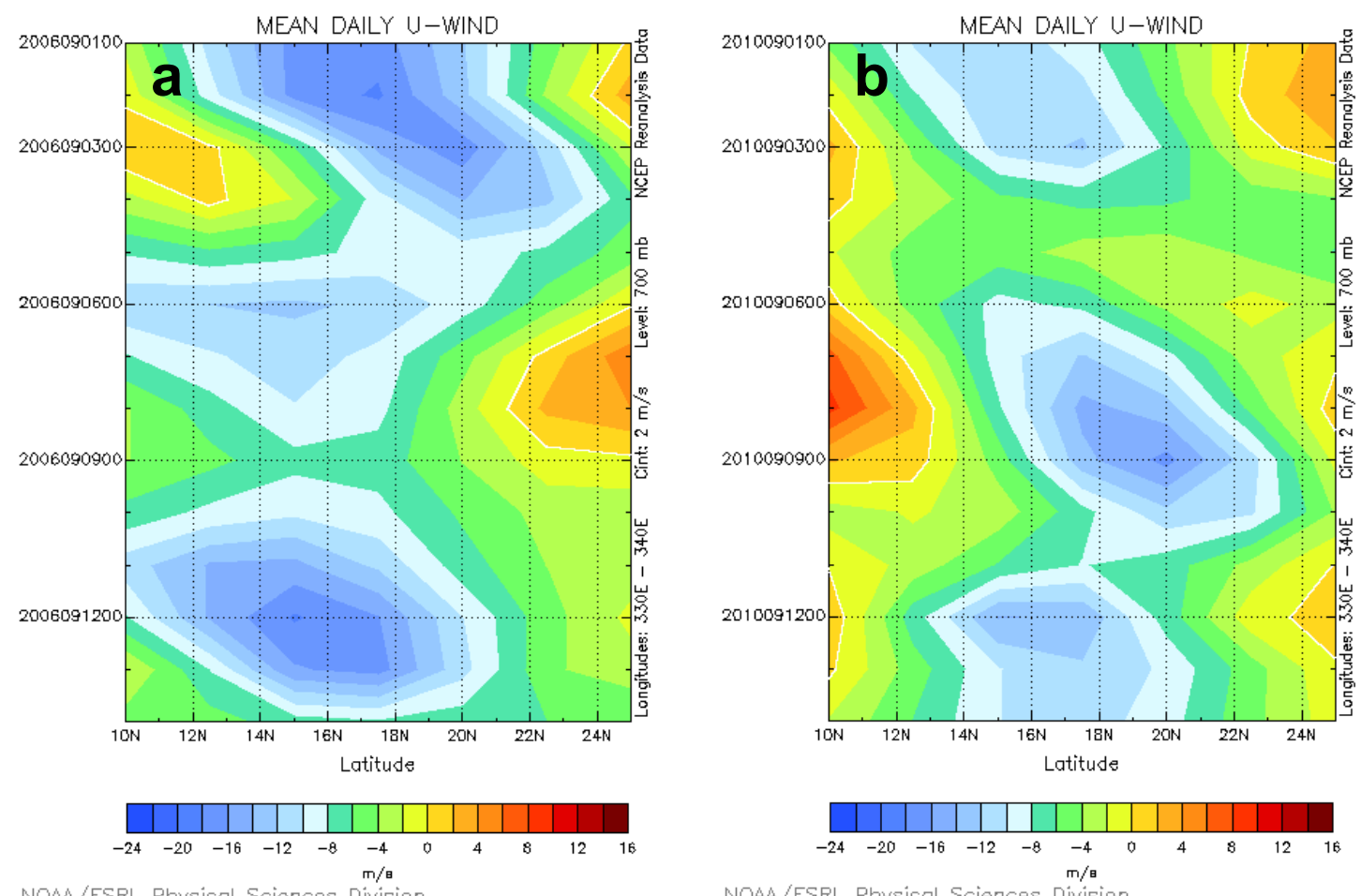

NOAA/ESRL Physical Sciences Division

NOAA/ESRL Physical Sciences Division
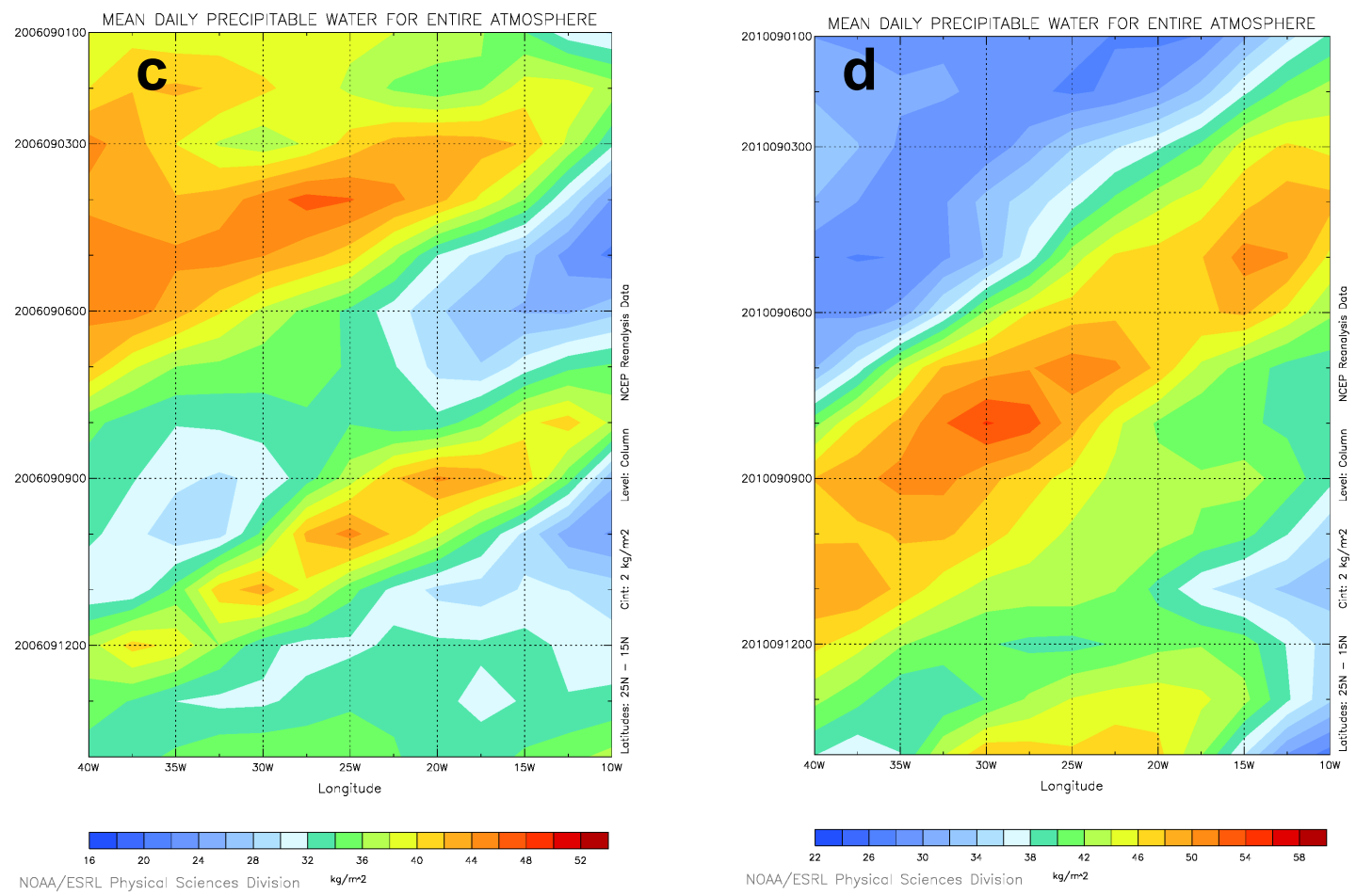

Figure 7: NCEP Reanalysis time-lat mean zonal wind (a) and (b), and time-lon daily precipitable water (c) and (d) for Helene and Julia, respectively. 

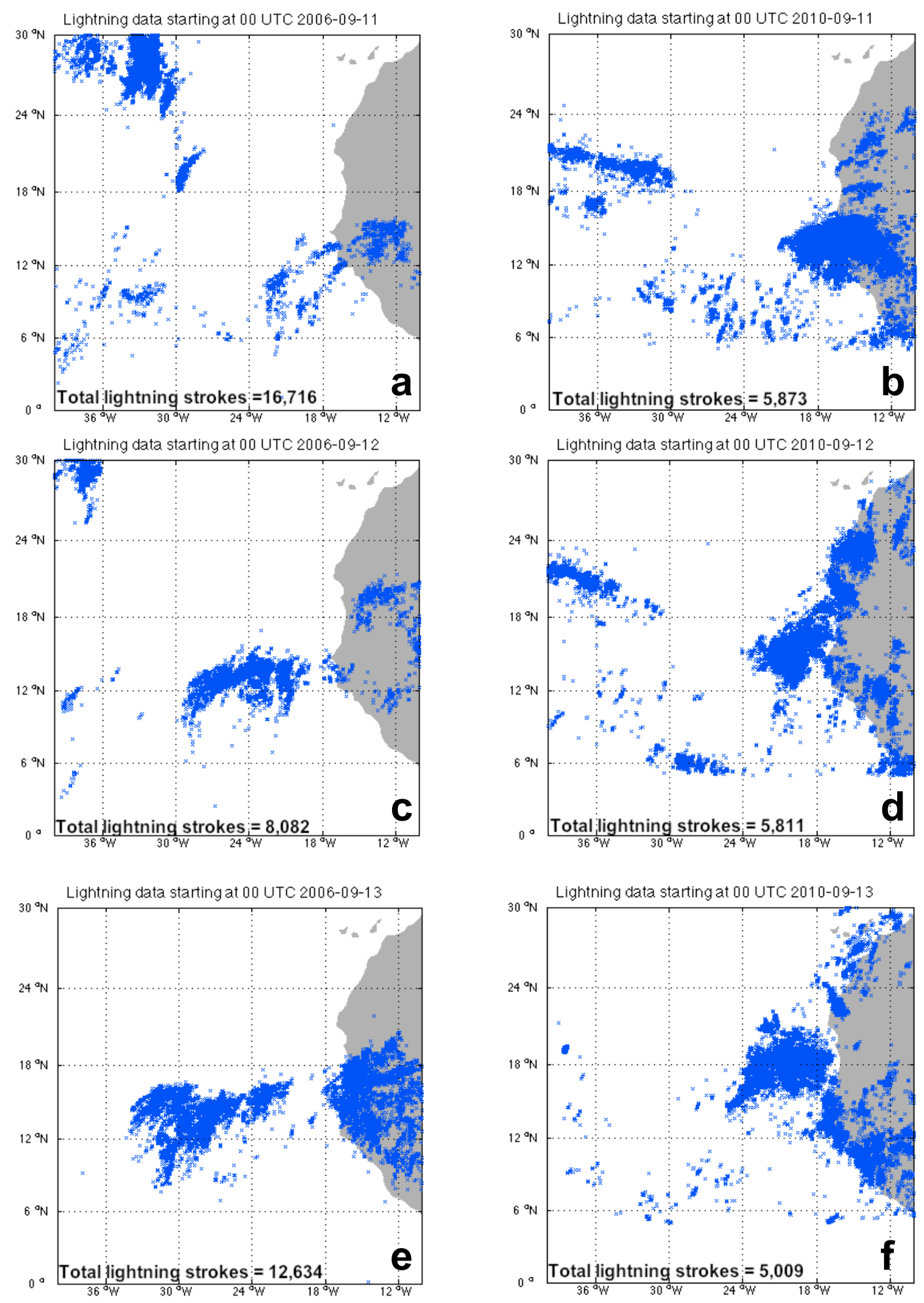

Figure 8: Daily total accumulated ATD lightning strokes from September 11 to 13, (a), (c) and (e) for Helene (2006), and (b), (d) and (f) for Julia (2010). 
Since large values of AOD represent a strong SAL, and Saharan dust particles also commonly act as $\mathrm{CCN}$, dust particles should increase lightning activities through the modification of cloud microphysics (Twohy et al. 2009 and Yuan et al. 2011). In order to further investigate the linkage between AOD and lighting strokes, a comparison between AOD and lightning strokes was conducted. Figures $9 \mathrm{a}$ and $9 \mathrm{~b}$ illustrate the time evolution of the area averaged AOD based on the predefined nine boxes (cf. Fig. 1) for TD 8 and TD 12, respectively. The time evolution of AOD of the two events demonstrated the distribution of aerosols quantitatively. Initially, a larger AOD $(0.4 \sim$ 0.6) was observed from September 10 to 12,2006 around $10^{\circ} \mathrm{W}-30^{\circ} \mathrm{W}$ and $10^{\circ} \mathrm{N}-30^{\circ} \mathrm{N}$ for TD 8 (Fig. 9a). On the other hand, a moderated amount of AOD (0.2 to 0.4 ) was observed during the formation of TD 12 from September 10 to 13, 2010 (Fig. 9b). Nevertheless, the most vigorous area with AOD located in $10^{\circ} \mathrm{N}-20^{\circ} \mathrm{N}$ and $20^{\circ} \mathrm{W}-30^{\circ} \mathrm{W}$. The AOD analyses also suggested that the SAL barely reached north of the equator to $10^{\circ} \mathrm{N}$ for both cases.

To further examine the connection of AOD and lightning strokes, Fig. 10 shows the composite analyses of the two elements for the day before, during, and after TD was named. This analysis was based on the total amount of lightning strokes and AOD measured within the $10^{\circ} \mathrm{N}-20^{\circ} \mathrm{N}$ and $20^{\circ} \mathrm{W}-30^{\circ} \mathrm{W}$ region (i.e., the target area; cf Fig. 1a). The results suggest that the day before the formation of TD 8 (i.e., 11 September 2006), the target area had higher AOD ( $0.5-0.7)$ with almost no lightning strokes between $22^{\circ} \mathrm{W}-27^{\circ} \mathrm{W}$ (Fig. 10a). Subsequently, higher values of lightning strokes were observed during the following days (Figs. 10c and 10e). This result suggests that TD 8 was 
developed under the abundant residual dust particles (i.e., footprints) that acted as CCN sources, invigorating deep convection within the inner-core region of the cloud cluster. On the other hand, TD 12 did not have much CCN available due to a lower amount of dust particles $(\sim 0.3)$ in the target area (Fig. 10b). Therefore, lightning strokes in TD 12 were much less compared to TD 8 (cf. Fig. 10d-f). Nevertheless, higher values of lightning strokes occurred along coastal region (i.e., $30^{\circ} \mathrm{W}-10^{\circ} \mathrm{W}$ and $20^{\circ} \mathrm{N}-30^{\circ} \mathrm{N}$ ), which was consistent with the Meteosat-SAL analysis (Fig. 1b). It appears that TD 12 developed without large amounts of dust particles, but with lower wind shear (Table 2) and an organized MCS (Fig. 4b).

Overall, the AOD and lightning analyses for TD 8 demonstrated the time-lag connection in terms of positive contributions to TC-genesis. From the comparison of AOD and lightning, we can further summarize that the location (i.e., the target area) of strong versus weak dust outbreaks in association with lightning is essential when considering the impacts of the surrounding atmospheric environment on TC-genesis, for these two cases. Nevertheless contributions from thermodynamic processes associated with lightning are still in need of consideration. 
Area-Averaged Time Series (MOD08_D3.051)

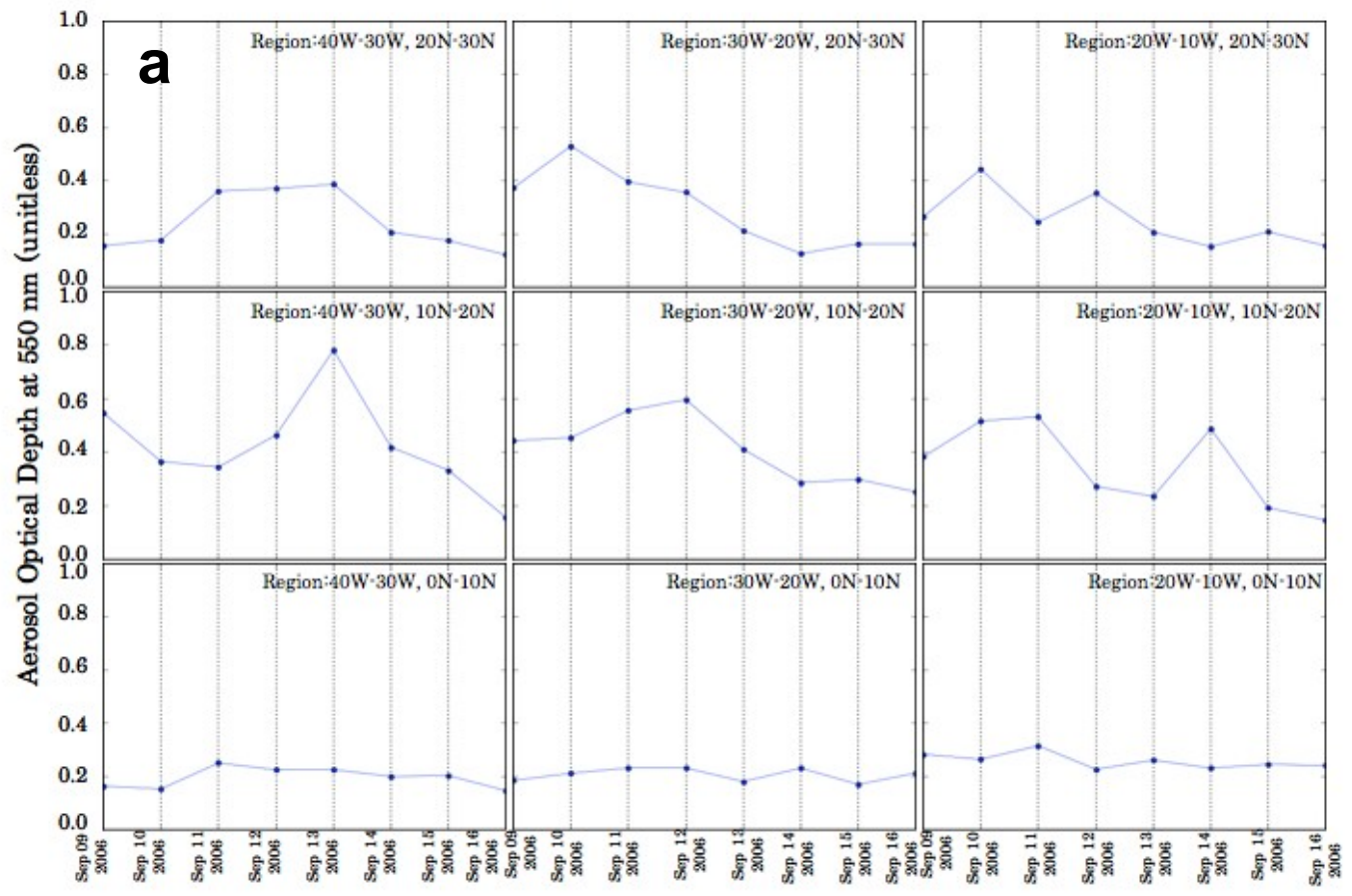

Area-Averaged Time Series (MOD08_D3.051)

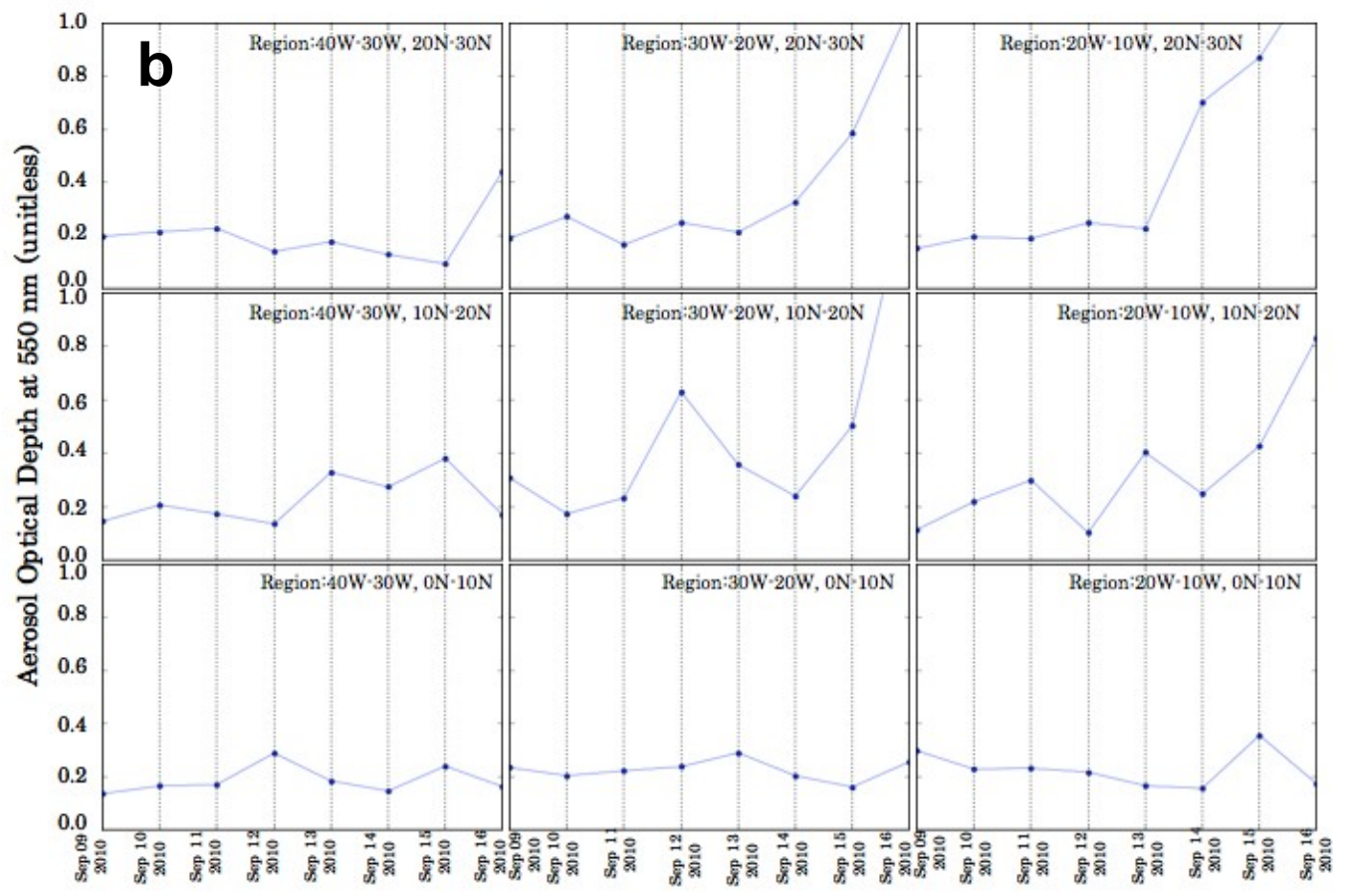

Figure 9: Area averaged AOD measurements from MODIS for (a) September 2006 (before, during and after formation of Helene 2006), and (b) September 2010 (before, during and after formation of Julia 2010). The nine boxes represent the entire domain from $10^{\circ}-40^{\circ} \mathrm{W}, 0^{\circ}-30^{\circ} \mathrm{E}$ divided into $10^{\circ} \times 10^{\circ}$ boxes. 

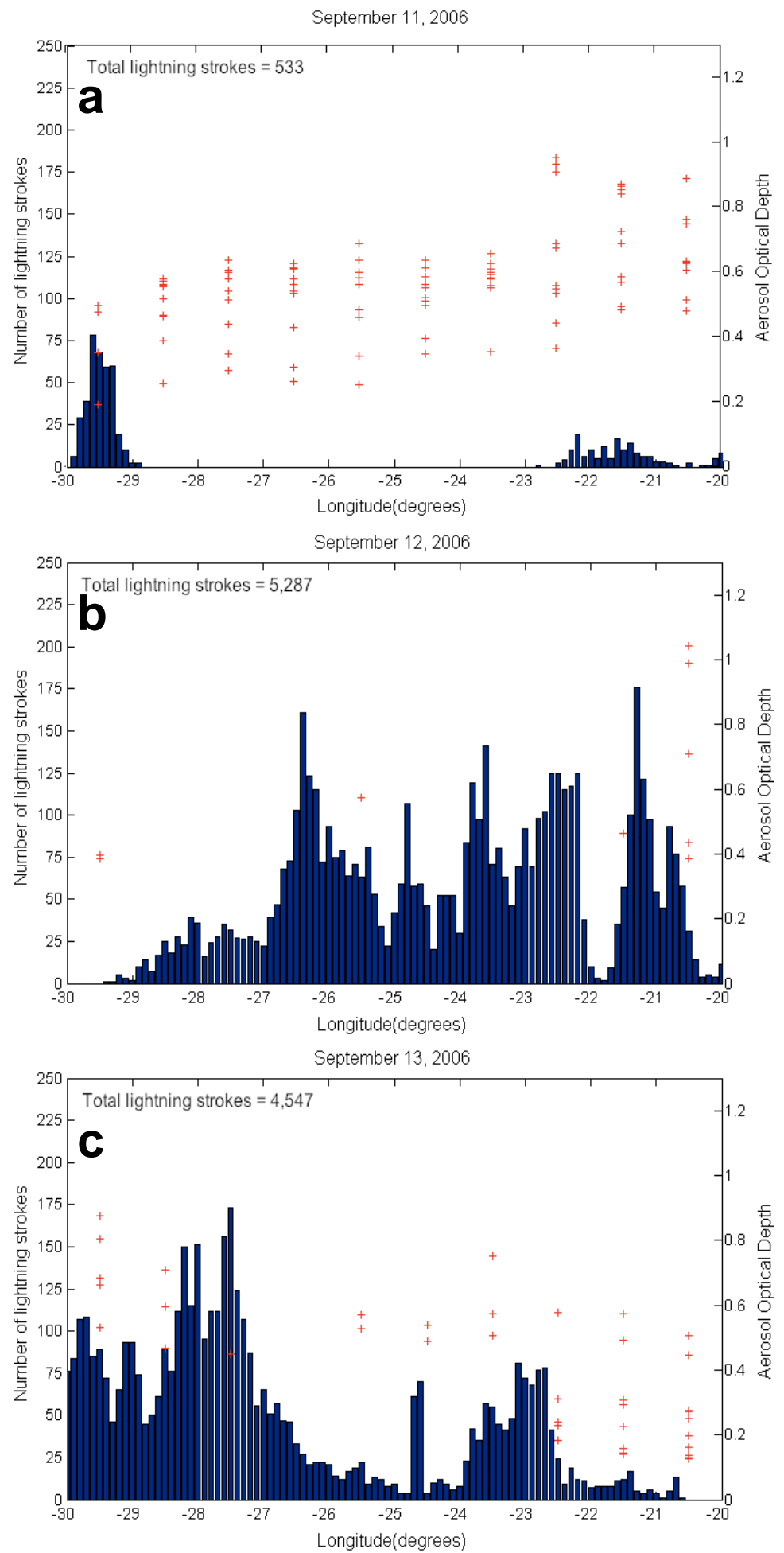

Figure 10: Comparison of ATD lightning strokes (blue bars) from Met Office and AOD (plus signs) from MODIS on the days before, during, and after the formation of TD 8 (Helene) 2006 and TD 12 (Julia) 2010. 

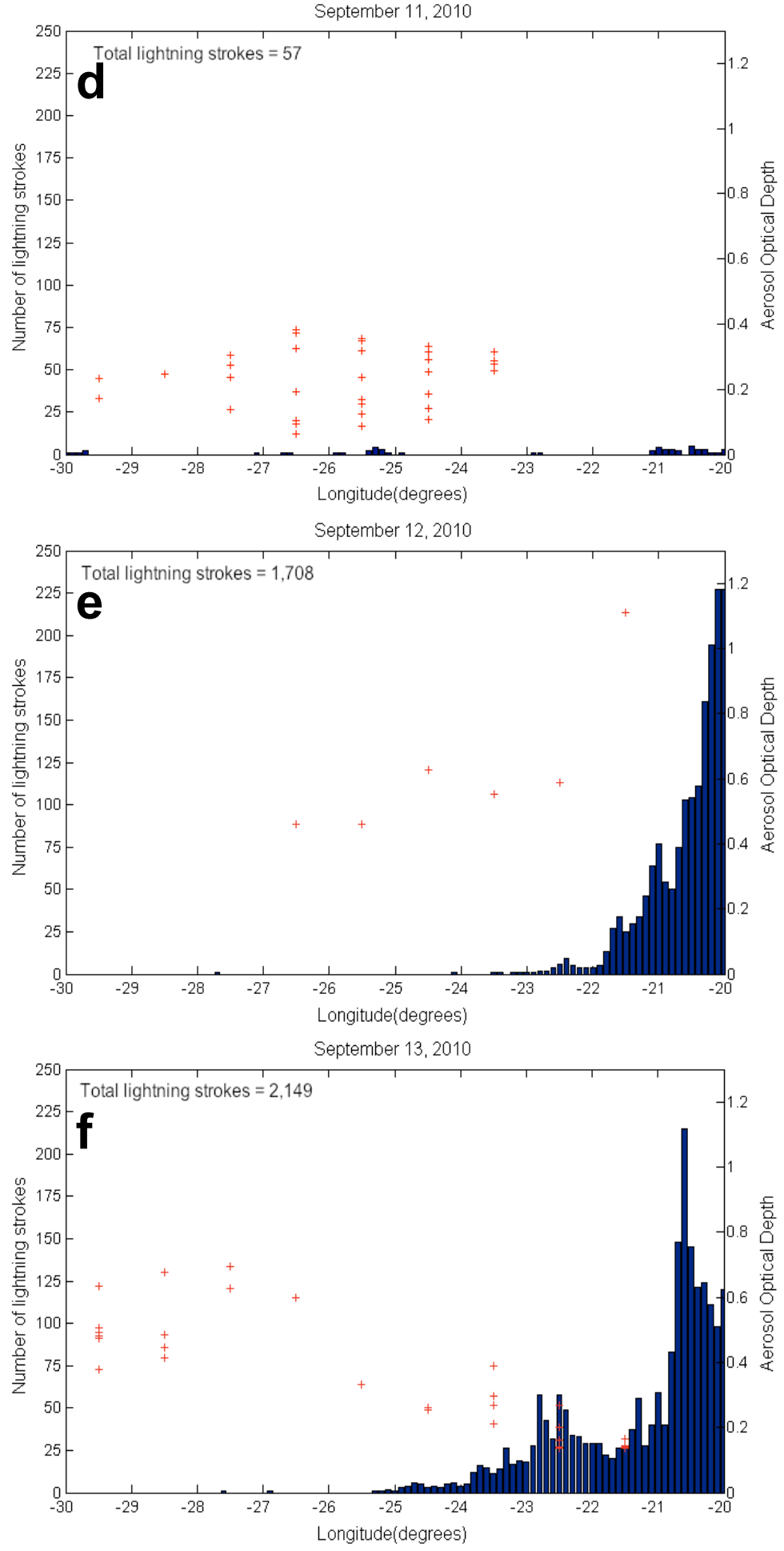

Figure 10: Continued. 


\section{Numerical Analysis Results \\ a. Control Experiment with WRF}

\section{1) POTENTIAL DEVELOPMENT}

The relative vorticity and the wind fields at $850 \mathrm{hPa}$ are analyzed for the 4 cases to observe the structure of the vortex (Fig. 11). The simulation results demonstrate high values of relative vorticity in Case \#1, Hurricane Helene (2006), with values greater than $40 \times 10^{-5} \mathrm{~s}^{-1}$. The cyclonic circulations and defined vortex expected from a developing system can be observed in Case \#1 (Fig. 11a). Case \#2, Hurricane Julia (2010), shows intermediate values of relative vorticity and the circular rotation and defined vortex characteristic of a developing system (Fig. 11b). Even if Case \#3, Non-Developed (2011), exhibits relative vorticity values greater than $50 \times 10^{-5} \mathrm{~s}^{-1}$ it does not exhibit signs of further development (Fig. 11c). Unlike Case \#1, Case \#3 does not show the defined rotation and vortex structure expected from a developing system. Instead, the center of rotation appears to be elongated towards the northeast (Fig. 11c). In the simulated radar reflectivity, as shown in Fig.12, a similar pattern than in the relative vorticity is depicted, in which Case \#1 has one of the highest values from the four cases, of $46.68 \mathrm{dbz}$. Case \#2 (Fig. 12b) also shows areas of high reflectivity as expected from a developing system. In addition, Case \#3 has the second highest value from the four cases, of $44.84 \mathrm{dbz}$ (Fig. 12c) and Case \#4 still does not show any signs of organization or development (Fig. 12d). 

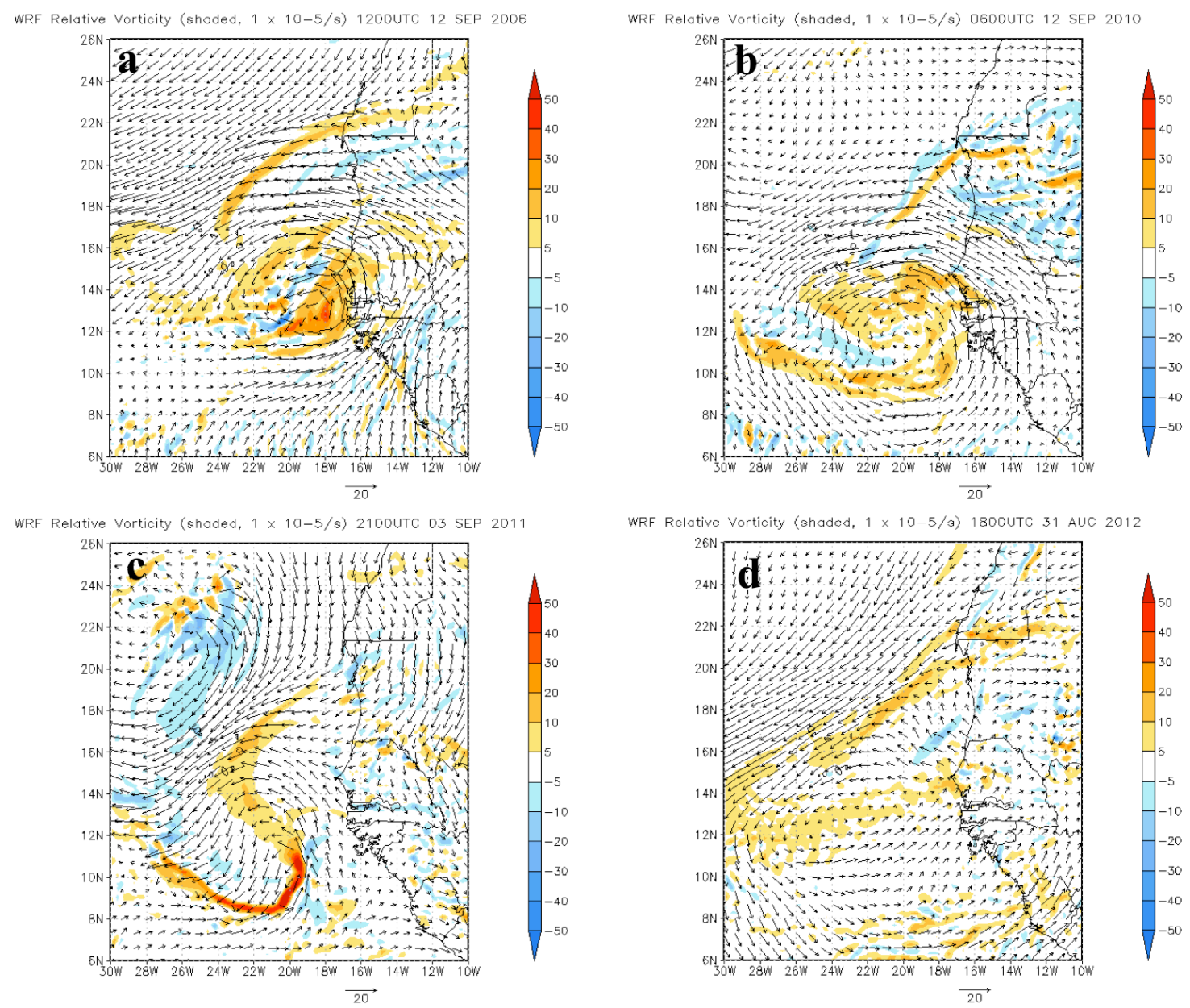

Figure 11. WRF $850 \mathrm{hPa}$ relative vorticity and wind vectors for (a) Case \#1 Helene 2006, (b) Case \#2 Julia 2010, (c) Case \#3 Non- Developed 2011, and (d) Case \#4 NonDeveloped 2012. 

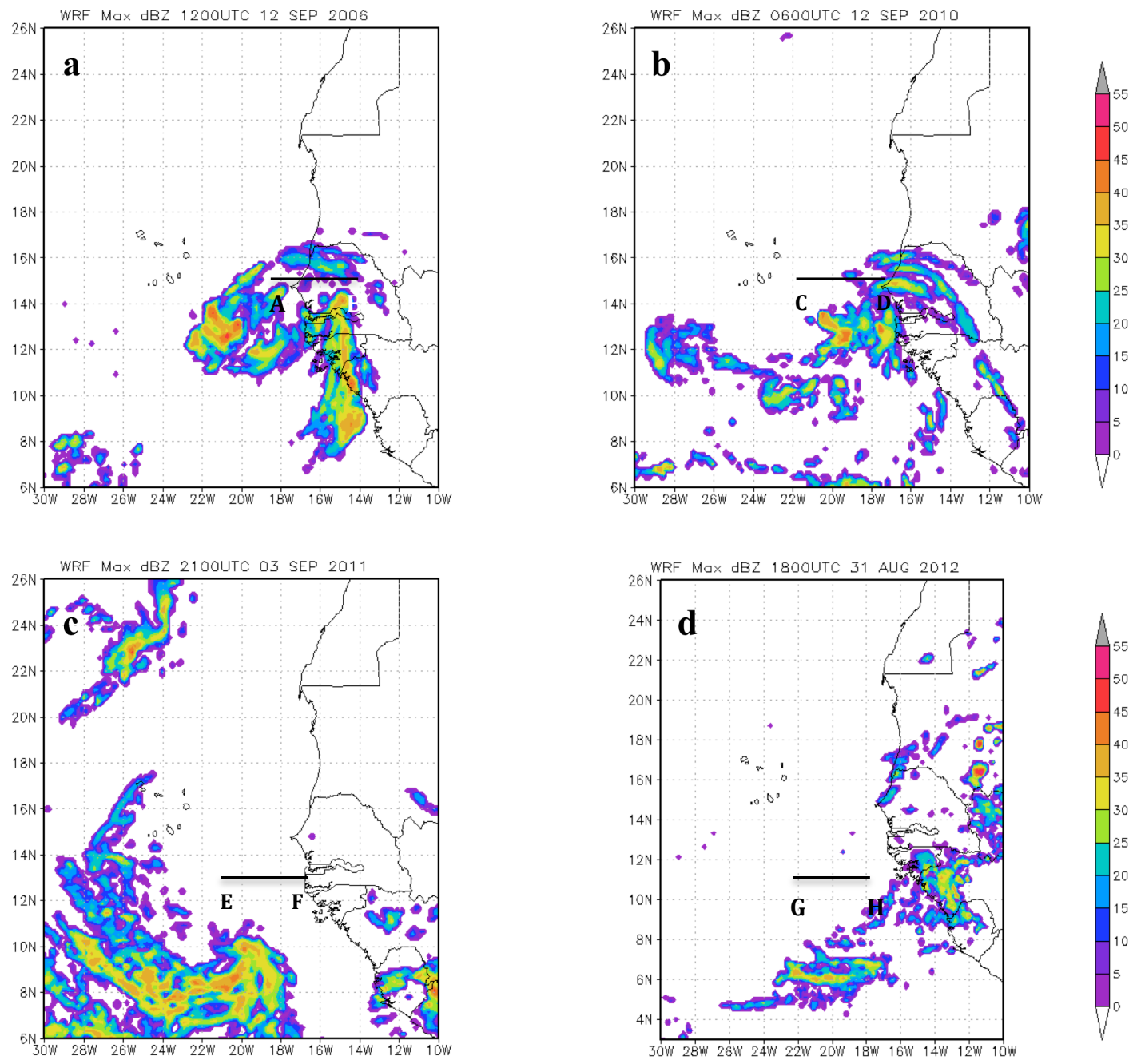

Figure 12. WRF radar reflectivity (dBZ) for (a) Case \#1 Helene 2006, (b) Case \#2 Julia 2010, (c) Case \#3 Non- Developed 2011, and (d) Case \#4 Non-Developed 2012. 


\section{b. Dust Sensitivity Experiment With WRF-CHEM}

\section{1) POTENTIAL DEVELOPMENT}

In the sensitivity experiment runs created with WRF-CHEM we could observe a slight improvement in the representation of the vortex and the structures of the cloud clusters. It can be seen that the highest values of relative vorticity still exist in Case \#1 and Case \#3 (Fig. 13). Case \#1 appears to have additional areas of high relative vorticity and shows a slight increase in the maximum value $\left(69.19 \times 10^{-5} \mathrm{~s}^{-1}\right)$ in comparison to the one observed from the regular WRF simulation $\left(42.87 \times 10^{-5} \mathrm{~s}^{-1}\right)$. In addition, it proved to have additional areas of high relative vorticity. Case \#3 appears to have a slight decrease in the maximum value of relative vorticity than the one observed in the control run. Figure 14 demonstrates the radar reflectivity and the available dust particles from the WRF-CHEM model. In Case \#1 (Fig. 14a) the dust outbreak (black dotted contours), and the transition of the dust particles from the continental environment towards the Atlantic basin can be easily identified. This result is in agreement with the satellite observation analyses shown in Fig.1a. Additionally, an intrusion of dust particles $\left(2 \mu \mathrm{g} \mathrm{kg}^{-1}\right.$ dry air) into the north and west regions of the developing system is well simulated, which cannot be clearly observed in Fig.1a. Even if Case \#2, Case \#3, and Case \#4 (Figs. 14b, 14c, and 14d), show the transition of the dust particles from the continental sources towards the Atlantic basin, the evidence of dust intrusion into the cloud clusters is not significant. Still, a difference between the extension of the distribution of the dust from the Meteosat satellite imagery and the WRF-CHEM results can be observed in Fig. 14d. The Meteosat 
imagery shows a larger area of coverage, while the WRF-CHEM results show a more conservative and concentrated distribution for Case \#4.
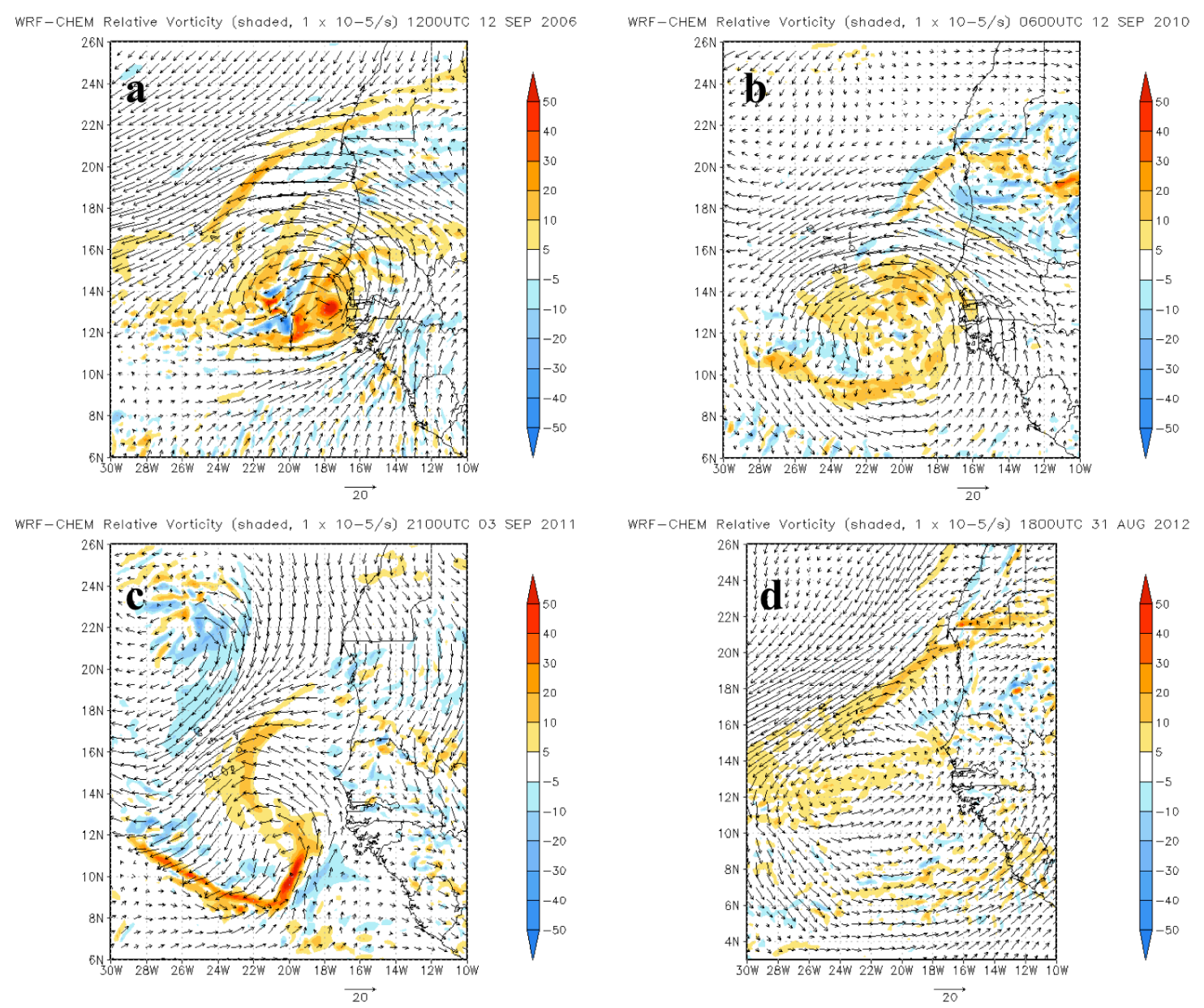

Figure 13. WRF-CHEM $850 \mathrm{hPa}$ relative vorticity and wind vectors for (a) Case \#1 Helene 2006, (b) Case \#2 Julia 2010, (c) Case \#3 Non- Developed 2011, and (d) Case \#4 Non-Developed 2012. 

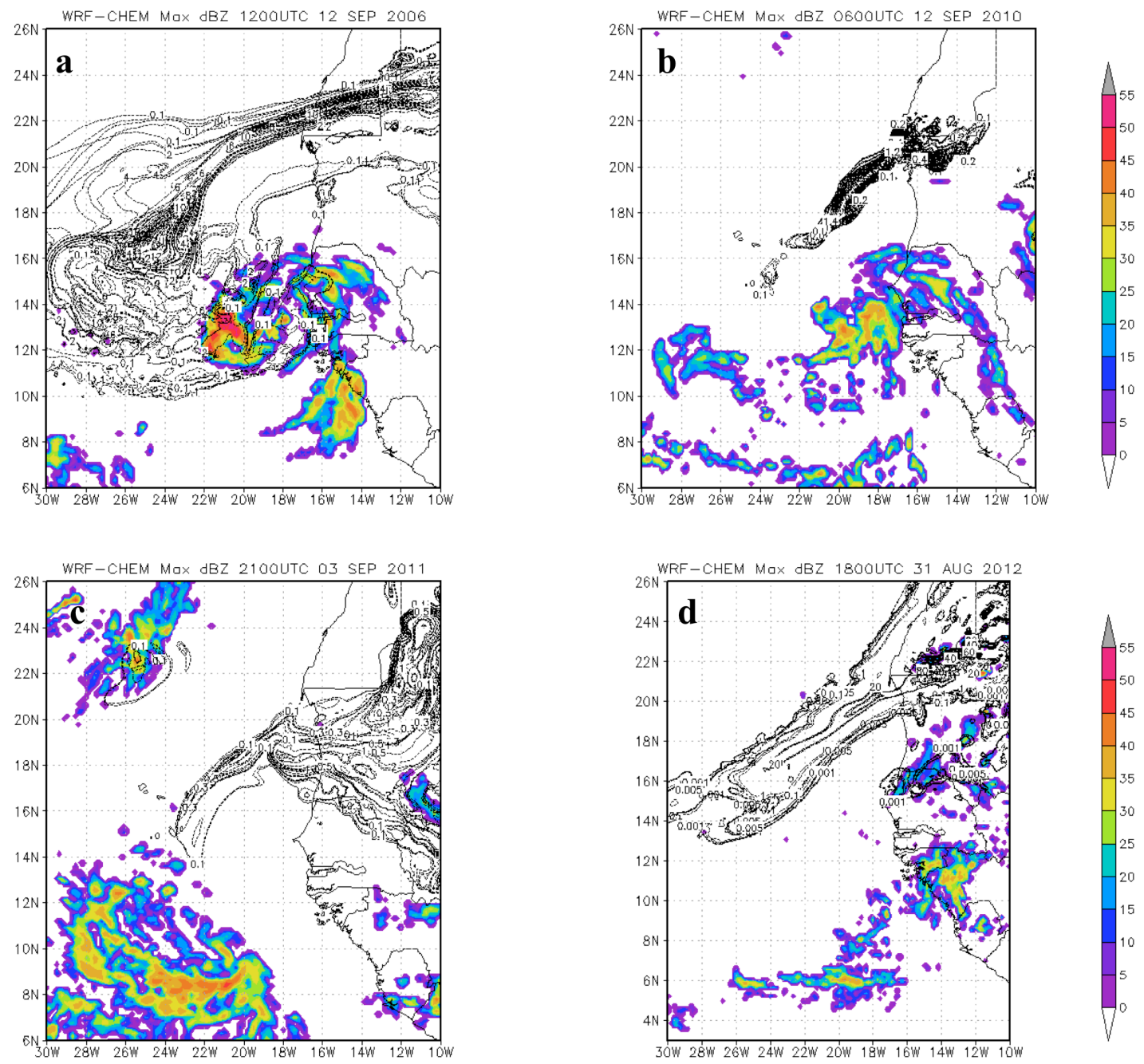

Figure 14. WRF-CHEM radar reflectivity (shaded, dbz) for (a) Case \#1 Helene 2006, (b) Case \#2 Julia 2010, (c) Case \#3 Non- Developed 2011, and (d) Case \#4 Non-Developed 2012. Dust particles ( $\mu \mathrm{g} \mathrm{kg}^{-1}$ dry air) are represented by the black dotted contours. 


\section{2) VERTICAL DISTRIBUTION OF MOISTURE}

The total amounts of the moisture variables are presented in Table 3. These amounts represent the totals from the integrated vertical column of all the points in each of the cross sections designated in Fig. 12. From the two developed cases, Case \#1 (strong dust outbreak conditions) has the highest total values of rainwater from both models (i.e., $16.28 \mathrm{~g}$ and $63.62 \mathrm{~g}$ for the WRF and WRF- CHEM models, respectively) in comparison to the values of Case \#2 (15.44 $\mathrm{g}$ and $15.58 \mathrm{~g}$ for the WRF and WRF-CHEM models, respectively). The maximum value from the WRF-CHEM simulation is almost four times the total value for the regular WRF result, which suggests the participation of dust particles as $\mathrm{CCN}$ in rain production. Even if Case \#3 and Case \#4 did not develop, they show high values of total rain water (Table 3 ) from the cloud bands that did develop but dissipated soon after.

From the cases that developed, cross sections were conducted to analyze the vertical distribution of the moisture variables (vapor, cloud water, ice, and rain) and their interactions with the dust particles. Figures $15 \mathrm{a}$ and $15 \mathrm{c}$ show slightly similar conditions, but with differences in the coverage and the maximum value of the moisture variables for Case \#1. The vertical distribution of the dust particles throughout the cloud band demonstrates to have amounts as high as $6.36 \mu \mathrm{g} \mathrm{kg}^{-1}$ dry air (Fig.15c). In contrast, an intrusion of dust particles cannot be found for the WRF-CHEM simulation of Case \#2 

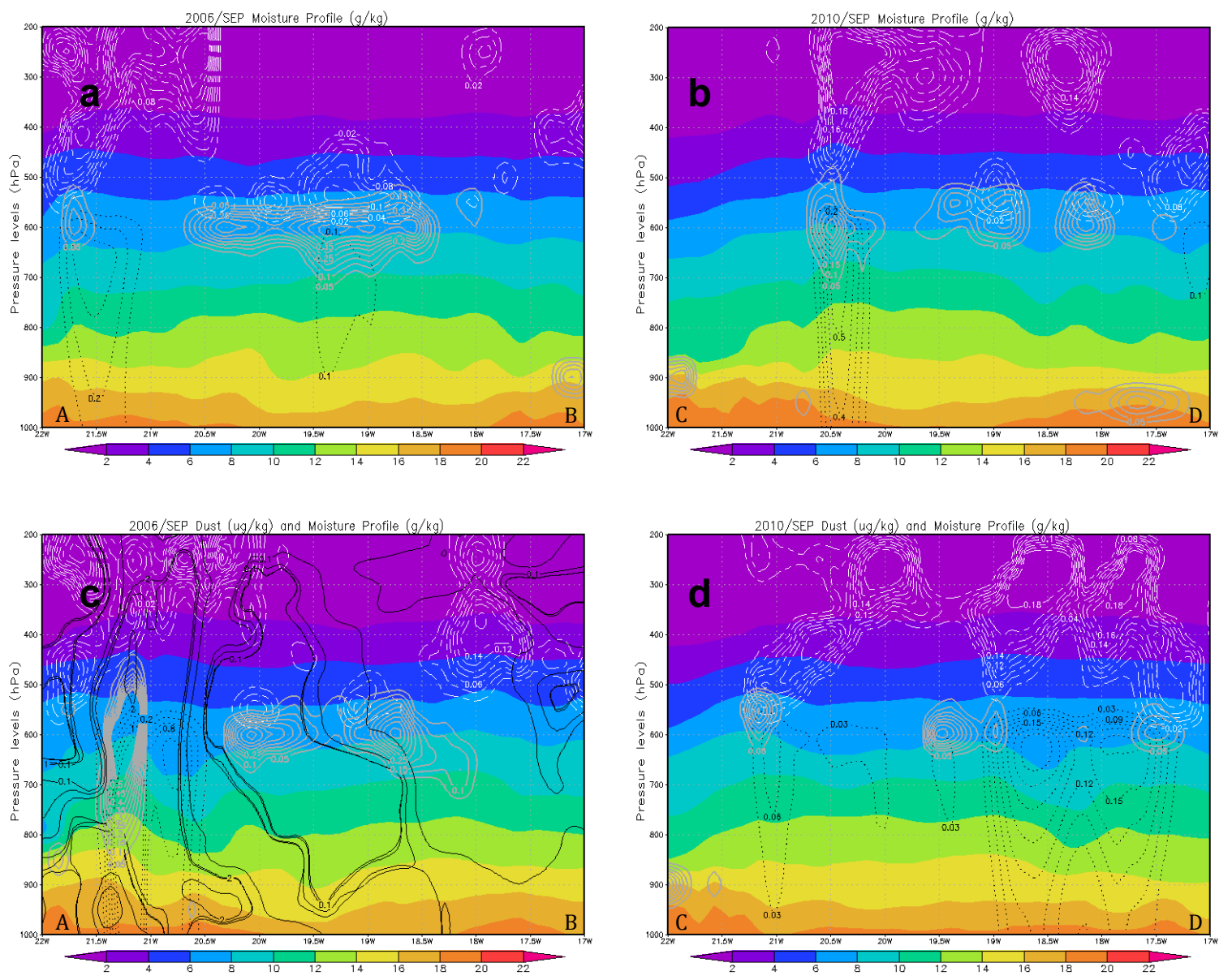

Figure 15. Moisture profiles for Case \#1 Helene 2006 (left column), and Case \#2 Julia 2010 (right column), from the WRF ( $a$ and $b$ ) and WRF-CHEM (c and d) models. The moisture variables $\left(\mathrm{g} \mathrm{kg}^{-1}\right)$ included are: water vapor mixing ratio (shaded), rain water (black dotted line), ice (white long dash-short dash line), and cloud water (gray solid). Dust particles ( $\mu \mathrm{g} \mathrm{kg}^{-1}$ dry air) from the bins are represented with the black solid line.

(Fig. 15d). Furthermore, in comparison to the regular WRF results (Fig. 15b), the WRFCHEM results (Fig. 15d) present evidence of the impact of the aerosol and chemistry calculations included in the model in the difference of the location and amounts of the moisture variables. Even though there is no sign of dust particles acting as CCN (Fig. 15d), amounts of rain water distributed from surface to approximately $550 \mathrm{hPa}$ and horizontally from $17.5^{\circ} \mathrm{W}$ to $19^{\circ} \mathrm{W}$ were simulated that were not modeled from the WRF-ARW experiment. 
Table 3. Total amounts of the moisture variables from the cross sections designated in Fig. 12. Note: The total amounts are not based in the grams in a $1 \mathrm{~kg}$ of dry air, but in the grams in the integrated column of all the points of each cross section.

\begin{tabular}{|l|l|l|l|l|l|l|l|l|}
\hline & \multicolumn{2}{|c|}{ Helene 2006 } & \multicolumn{2}{c|}{ Julia 2010 } & \multicolumn{2}{c|}{ Non-Dev 2011 } & \multicolumn{2}{c|}{ Non-Dev 2012 } \\
\cline { 2 - 10 } & WRF & $\begin{array}{c}\text { WRF- } \\
\text { CHEM }\end{array}$ & WRF & $\begin{array}{c}\text { WRF- } \\
\text { CHEM }\end{array}$ & WRF & $\begin{array}{c}\text { WRF- } \\
\text { CHEM }\end{array}$ & WRF & $\begin{array}{c}\text { WRF- } \\
\text { CHEM }\end{array}$ \\
\hline Qvapor & 5101.97 & 5149.21 & 5164.07 & 5180.91 & 4814.53 & 4736.89 & 4911.64 & 4860.38 \\
\hline Qrain & 16.28 & 63.62 & 15.44 & 15.58 & 52.49 & 49.22 & 35.94 & 28.24 \\
\hline Qcloud & 10.10 & 13.76 & 8.16 & 4.13 & 29.53 & 18.01 & 11.14 & 9.44 \\
\hline Qice & 10.45 & 10.04 & 9.04 & 13.34 & 13.54 & 15.75 & 19.08 & 13.02 \\
\hline
\end{tabular}

\section{3) AEROSOL FEEDBACK}

Case \#1, Hurricane Helene (2006), was selected to further analyze the sensitivity of the WRF-CHEM model to different configurations, such as including aerosol feedback in the model simulation. The simulated downward shortwave radiation flux (Fig. 16) was analyzed to determine the impact of the aerosols feedback and the aerosols direct effect. The maximum simulated downward shortwave radiation flux in clear sky (no clouds) conditions is $1029.87 \mathrm{~W} \mathrm{~m}^{-2}$ (Fig.16a) for the three different configurations (regular WRF, WRF-CHEM without aerosol feedback, and WRF-CHEM with aerosol feedback). On the other hand, a decrease in downward shortwave radiation can be observed, as the system starts moving into the selected area on 12 September 2006 (Fig. 16b). The simulation with aerosol feedback (Fig 16b, black solid line) demonstrates the lowest value of downward shortwave radiation $\left(40.45 \mathrm{~W} \mathrm{~m}^{-2}\right)$ at the simulated maximum radar reflectivity region on the time of formation (12 UTC 12 September 2006). The WRFCHEM simulation without aerosol feedback has the second lowest value of $59.43 \mathrm{~W} \mathrm{~m}^{-2}$ and the WRF simulation has the highest value of $149.26 \mathrm{~W} \mathrm{~m}^{-2}$ (Fig. 16b, blue dotted line and red dot-dash line, respectively). 

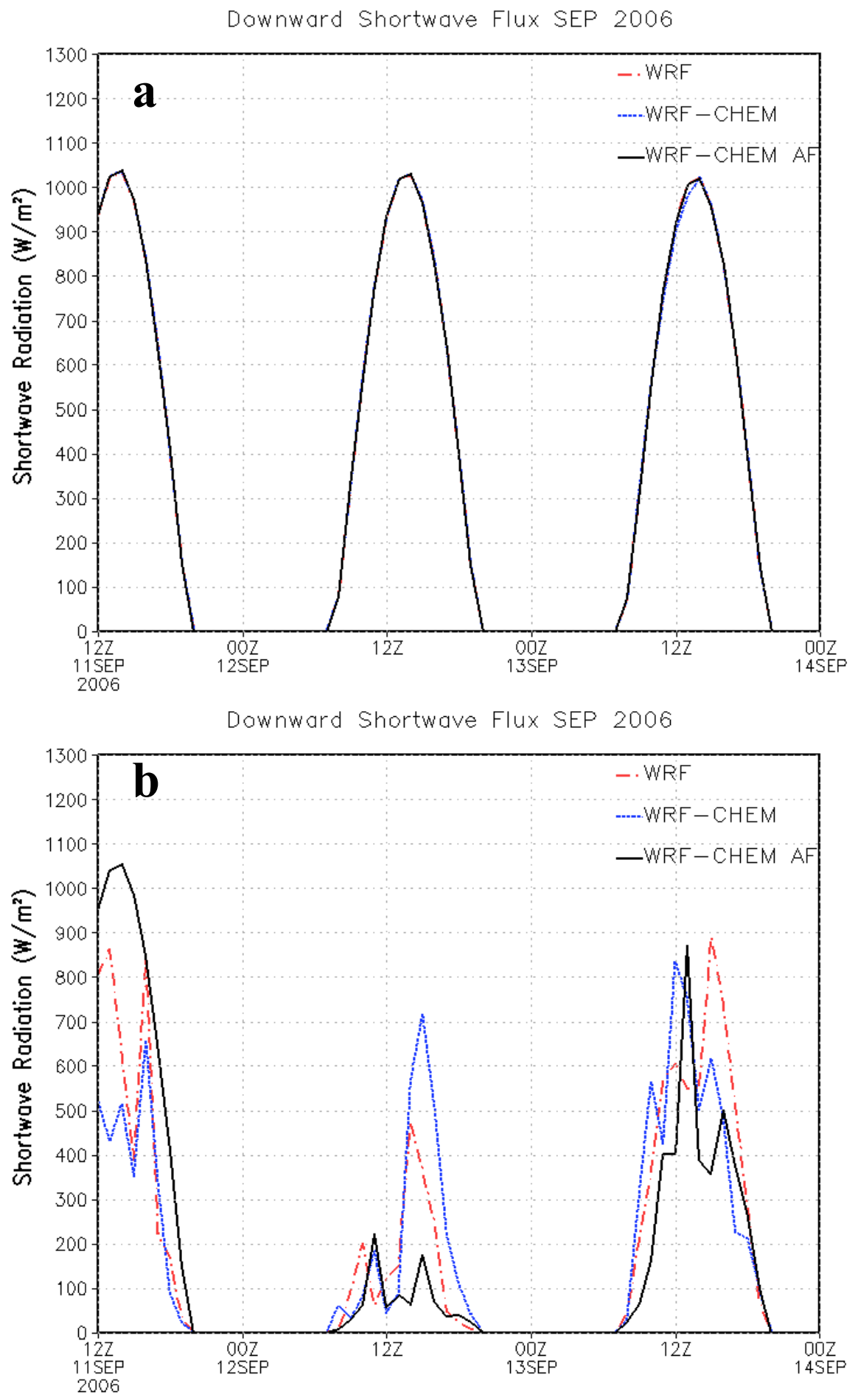

Figure 16. Simulated downward shortwave flux at ground surface $\left(\mathrm{W} \mathrm{m}^{-2}\right)$ for (a) clear sky (no clouds) and (b) at a point of maximum radar reflectivity located at latitude $13^{\circ} \mathrm{N}$ and longitude $21^{\circ} \mathrm{W}$. 

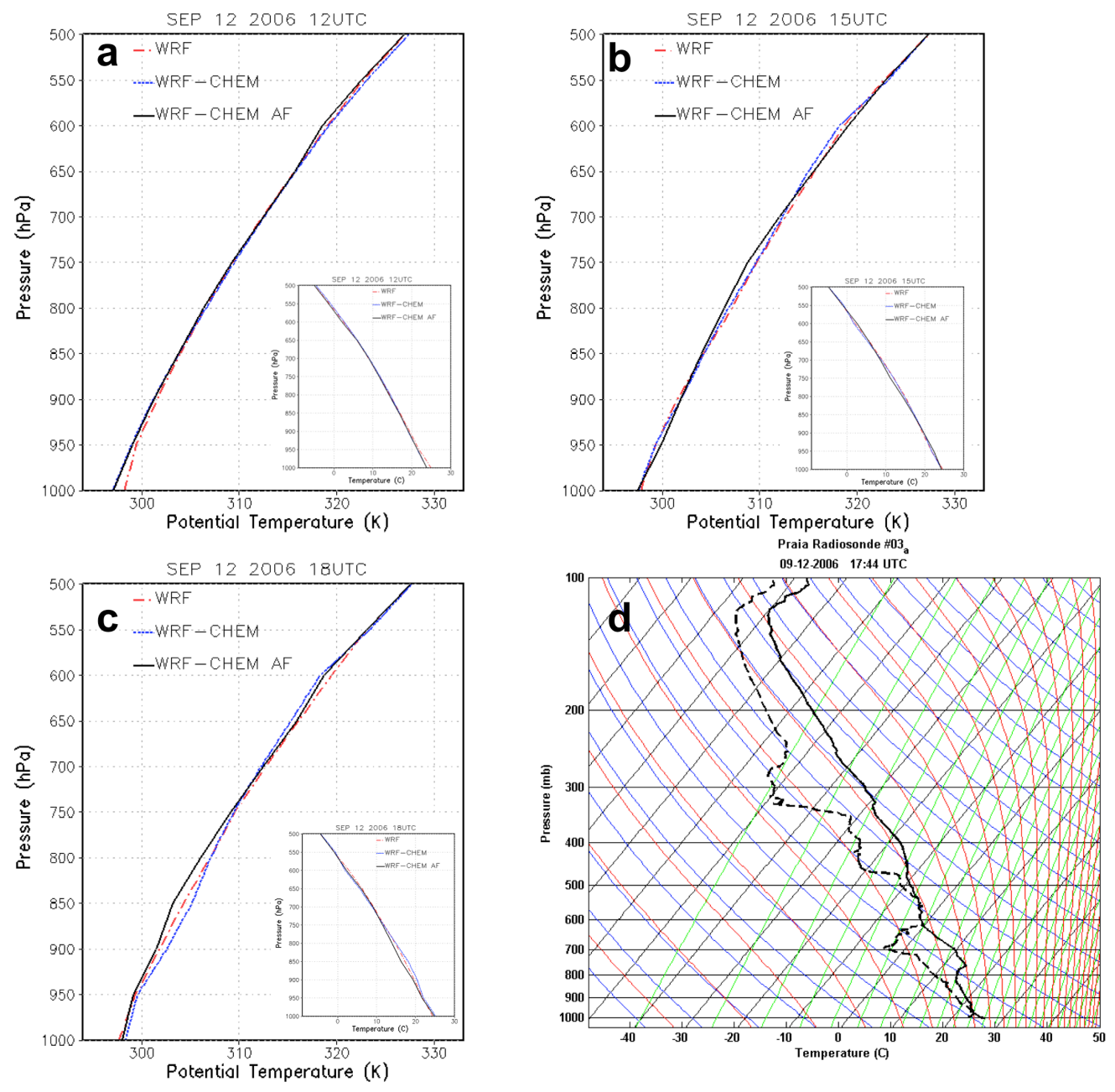

Figure 17. Simulated Potential Temperature $(\mathrm{K})$ at the same location than Fig.16b for 3 different intervals after the formation of Case \#1 (a) at 1200UTC, (b) at 1500 UTC, (c) 1800 UTC and (d) a temperature profile from a sounding launched north of the system at Praia, Cape Verde. 

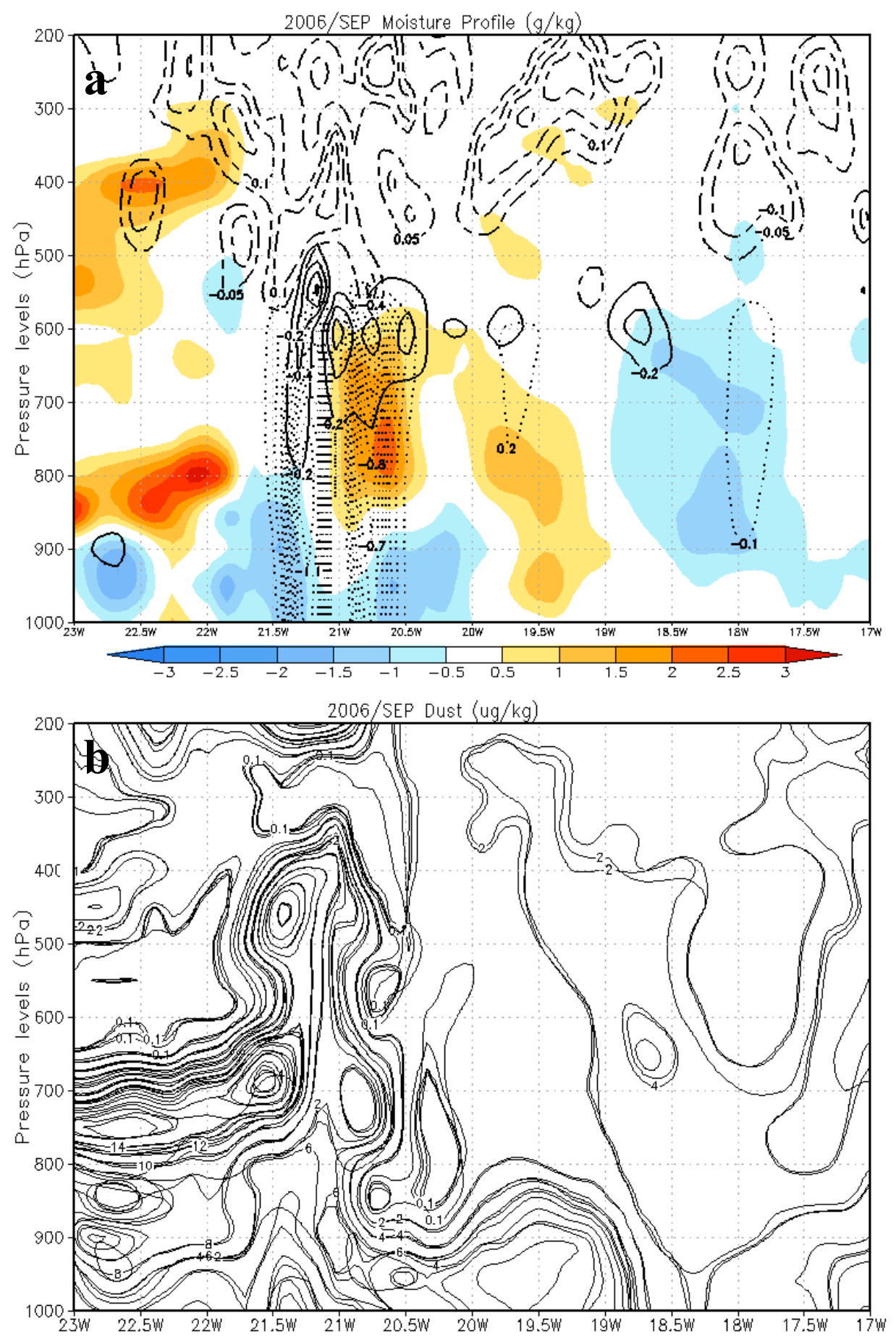

Figure 18. Difference between WRF-CHEM simulations with and without aerosol feedback of (a) moisture profiles for Case \#1 Helene 2006 and (b) dust particles ( $\mu \mathrm{g} \mathrm{kg} \mathrm{kg}^{-1}$ dry air). The moisture variables $\left(\mathrm{g} \mathrm{kg}^{-1}\right)$ included are: water vapor mixing ratio (shaded), rain water (dotted line), ice (long dash-short dash line), and cloud water (solid). 
The potential temperature profiles shown in Fig. 17 demonstrate differences in potential temperature that correspond to the differences in shortwave radiation from Fig. 16b. The highest difference in potential temperature is of $2 \mathrm{~K}$ between the simulation that does not include aerosol feedback (Fig. 17c blue line) and the simulation with aerosol feedback on (Fig. 17c black line). This difference in potential temperature is located at an area in which dust particles are found, around 900 and $800 \mathrm{hPa}$. This suggests that the dust-radiation feedbacks may have affected the distribution of heat at a local scale for Case \#1. Even if the sounding in Fig. 17d from Praia, Cape Verde is northward of the selected location for the temperature profiles, it provides a close measurement of the temperature at the formation stage of the tropical system. The sounding temperature of $\sim 25^{\circ} \mathrm{C}$ is in agreement with the temperatures simulated by the models. Overall, the three simulations (WRF, WRF-CHEM, and WRF-CHEM AF) had very similar values and patterns of potential temperature and temperature.

The difference between the moisture variables from the WRF-CHEM simulation with aerosol feedback and the ones from the WRF-CHEM simulation without aerosol feedback can be observed in Fig.18a. The simulation with aerosol feedback showed a decrease in the total rain amount of almost $50 \%$ in comparison to the WRF-CHEM run without aerosol feedback. The decrease in rain water can be observed at different areas of the vertical profile of Helene (2006) in Fig.18a, represented by the black dotted lines with the negative values. Additionally, the difference between the dust bins of the WRFCHEM simulation with aerosol feedback and the ones from the WRF-CHEM simulation without aerosol feedback can be observed in Fig.18b. The dust bins amounts 
demonstrated maximum values of more than three times the maximum values of the simulation without aerosol feedback. Areas with high dust content present high values of water vapor, suggesting that the dust particles could be acting as $\mathrm{CCN}$. Although there may have been a high concentration of $\mathrm{CCN}$, the decrease in rain water previously mentioned suggests that the dust particles may have surpassed a certain level (threshold), in which the environment would had become more stratiform (less precipitable water) instead of convective (more precipitable water).

\section{4) HIGHER RESOLUTION}

The resolution of the simulations was increased to $5 \mathrm{~km}$ to analyze any event that could have been smoothed by the coarser resolution $(15 \mathrm{~km})$. The different scenarios simulated for the day of formation of Case \#1 are presented in Fig.19. There is a clear difference in the representation of the simulated maximum radar reflectivity between the 4 configurations. The results demonstrated by Figs. 19b and 19c (without and with aerosol feedback, respectively) are the closest to the satellite observations shown in Fig.1. Additionally, the results from the simulations without and with aerosol feedback generated the closest values of sea level pressure $(1005.1 \mathrm{hPa}$ and $1004.6 \mathrm{hPa}$, respectively) to the observations $(1007 \mathrm{hPa})$. On the other hand, the results demonstrated in Fig.18d have a higher intensity and a more eastward position than the observations. 

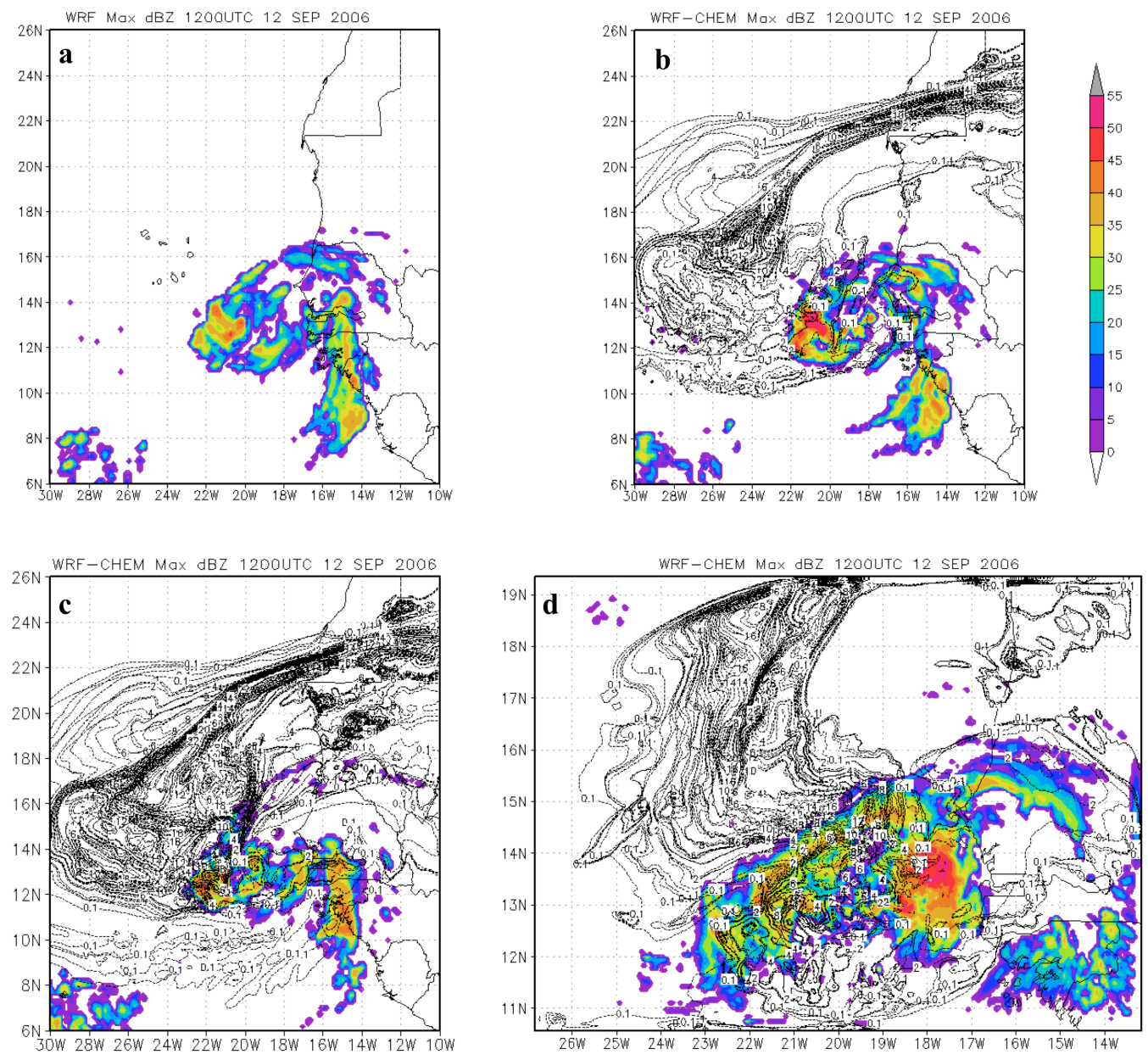

Figure 19. Comparison of the four different simulated scenarios of Case \#1 Helene 2006. Simulated radar reflectivity (shaded, dBZ) of (a) WRF, (b) WRF-CHEM without aerosol feedback, (c) WRF-CHEM with aerosol feedback, and (d) WRF-CHEM with aerosol feedback at $5 \mathrm{~km}$ resolution (zoom in at the tropical system). Dust particles ( $\mu \mathrm{g} \mathrm{kg}^{-1}$ dry air) are represented by the black dotted contours.

\section{Conclusions and remarks}

This study examined the formation of two tropical cyclones under different Saharan dust outbreak intensities but with nearly identical location of formation. Even when considering the controversial role of the SAL in the TC-genesis and intensification process, as well as the role of deep convection in the inner-core region of storms, it was the intention of this work to utilize data from field campaigns (NAMMA and GRIP), 
remote sensing (Meteosat-SAL and CALIPSO), and NCEP reanalysis to evaluate the connection between the SAL and lightning strokes at the TC-genesis stage. The use of these two cases that developed under different environmental conditions (strong/weaker dust outbreak), but around the same spatial location and temporal frame, provided us with good insight of the differences in the behavior of the parameters during stages of TCgenesis. TD 8 (Hurricane Helene 2006) was named on 12 September 2006 at 1200 UTC under a strong dust outbreak in contrast to TD 12 (Hurricane Julia 2010), which was named on 12 September 2010 at 0600 UTC under a weaker dust outbreak. We hypothesized that footprints of the SAL occurred within the target area (i.e., $30^{\circ} \mathrm{W}-20^{\circ} \mathrm{W}$ and $10^{\circ} \mathrm{N}-20^{\circ} \mathrm{N}$ ) would invigorate convective activities (i.e., lightning) around the inner core of cloud clusters via CCN.

The NCEP reanalysis depicted that an MCS traversed the coast of West Africa, which was the precursor of TD 12. Although a closed low pressure existed prior to the formation of $\operatorname{TD} 8$, a stronger dust outbreak was also observed. Consequently, a welldefined AEJ was associated with the dust outbreak during the formation of TD 8. As a result of this AEJ, higher wind shear and less precipitable water occurred. Several radiosondes were launched at Cape Verde around the inner-core of the cloud clusters before, during, and after the formation of TD 8 and TD 12, respectively. The RH profiles demonstrated that TD 8 was able to hold higher moisture than TD 12 during the TCgenesis stage. Moreover, the AOD and lightning data analyses suggested that higher amounts of dust particles in the background environment could increase $\mathrm{CCN}$, helping the development of the system by invigorating deep convection. This footprint behavior 
of the dust particles as $\mathrm{CCN}$ source was observed in the day prior to the formation of TD 8 , but not on the day prior to the formation of TD 12. Instead, conditions on the day prior formation of lower vertical wind shear $\left(<\sim 5.0 \mathrm{~m} \mathrm{~s}^{-1}\right)$, lighter dust cover and a welldefined MCS were a favorable combination for the development of the system towards what became TD 12 in 2010.

Additionally, for the numerical analysis, two cases that did not develop under different environmental conditions were analyzed; Case \#3 in 2011 dissipated under weak dust outbreak conditions and Case \#4 in 2012 dissipated under strong dust outbreak conditions. The high values of total rain observed on the day of formation of Case \#1 Hurricane Helene (2006) suggest that the SAL dust particles are acting as CCN and contributing in the rain production in the system. This result suggests that the WRFCHEM model offers the benefit of showing the presence of dust inside of the cloud, or storm structure, which usually cannot be observed with satellite imagery. The WRFCHEM model did help identify the real location of the dust in areas that are misidentified as dust-laden regions in the satellite imagery, which are instead dominated just by dry air. Also, the WRF- CHEM model seems to recreate a more defined structure of the systems (or cloud clusters) than the regular WRF model. Furthermore, the WRF-CHEM model version 3.5.1 employed for the addition of the aerosol feedback to the simulation demonstrated higher amounts of dust particles than version 3.4.1. Therefore, this lead to the scattering of more shortwave radiation and reducing the amount of rain water produced. Lastly, conducting a simulation with a higher resolution did not provide results that were closer to the observations. The higher resolution simulation 
demonstrated a system with rapid intensification, which does not agree with the observations. Therefore, this result suggests the possibility of problems with the boundary conditions that could be solved by increasing the size of the simulation domain.

Overall, the results from the combination of various data analyses in this study support the notion that both systems developed under either strong or weak dust conditions. Therefore, we can conclude that the results from this study suggest that the Saharan dust layer is not a determining factor that affects the formation of tropical cyclones (i.e., TD 8 and TD 12). Contributions from thermodynamic aspects need to be further analyzed and will be included in the future work for this study. While the hypothesis was able to apply under strong dust condition (i.e., TD 8), other factors (e.g., pre-existing vortex and trough location) need to be included as well. Identifying a threshold value among the AOD, lightning, and wind shear would help to further depict a boundary between suppression (if any) due to dust particles and CCN production or vice versa.

Future work will involve the repetition of this analysis using different resolutions and microphysics schemes and use the WRF-CHEM to assimilate MODIS AOD into the simulations. The AOD will also be used to calculate the mass inside of the domain and compare it with the WRF-CHEM results. Furthermore, an additional part of this study will consist in the development of an idealized simulation to manipulate key variables that will help to improve the understanding of the impact of dust (aerosols) on tropical cyclone formation. The simulated dust concentration will be evaluated using dust mass relations (Ben-Ami et al. 2010) of AOD. 


\section{References}

Acker, J. and G. Leptoukh, 2007: Online analysis enhances use of NASA Earth science data. EOS, Transactions American Geophysical Union, 88, 14.

Ben-Ami, Y., I. Koren, Y. Rudich, P. Artaxo, S. T. Martin, and M. O. Andreae, 2010: Transport of North African dust from the Bodélé depression to the Amazon Basin: a case study. Atmos. Chem. and Phys., 10, 7533-7544.

Braun, S. A. 2010: Re-evaluating the role of the Saharan Air Layer in Atlantic tropical cyclogenesis and evolution. Mon. Wea. Rev., 138, 2007-2037.

Braun, S.A., and Coauthors, 2012: NASA's Genesis and Rapid Intensification Processes (GRIP) field experiment. Bull. Am. Meteorol. Soc. doi: 10.1175/BAMS-D-1100232.1

Carlson, T. N., and J. M. Prospero, 1972: The large-scale movement of Saharan air outbreaks over the northern equatorial Atlantic, J. Appl. Meteorol., 11, 283-297, doi:10.1175/1520-0450(1972)011<0283:TLSMOS>2.0.CO;2.

Cavazos-Guerra, C., and M. C. Todd, 2012: Model Simulations of Complex Dust Emissions over the Sahara during the West African Monsoon Onset, Advances in Meteorology, 2012, doi:10.1155/2012/351731.

Chen, S.H., S.H. Wang, and M. Waylonis, 2010: Modification of Saharan air layer and environmental shear over the eastern Atlantic Ocean by dust-radiation effects. $J$. Geophys. Res., 115, D21202, doi:10.1029/2010JD014158.

Chou, M.-D., and M. Suarez, 1994: An efficient thermal infrared radiation parameterization for use in general circulation models. NASA Tech. Mem. 104606, 3, Technical Report Series on Global Modeling and Data Assimilation. 1-85.

CIMSS Tropical Cyclone Team, cited 2013: Saharan Air Layer (SAL)- Product Description. [Available online at http://tropic.ssec.wisc.edu/misc/sal/info.sal.m8split.html.]

Creamean J. M., K. J. Suski et al. 2013: Dust and biological aerosols from the Sahara and Asia influence precipitation in the Western U.S., Science, 339, 1572-1578. 
DeMaria, M., M. Mainelli, L. Shay, J. Knaff, and J. Kaplan, 2005: Further improvements to the Statistical Hurricane Prediction Scheme (SHIPS). Wea. Anal. Forecasting, 20, 531- 543.

Drame, M., G. S. Jenkins, M. Camara, and M. Robjhon, 2011: Observations and simulation of a Saharan air layer event with a midtropospheric dust layer at Dakar, Senegal, 6-7 July 2010. J. Geophys. Res.,116, D21204, doi:10.1029/2011JD016368.

Dunion, 2011: Rewriting the Climatology of the Tropical North Atlantic and Caribbean Sea Atmosphere. J. Climate, 24, 893-908.

Dunion, J.P., and C. S. Velden, 2004: The impact of the Saharan air layer on Atlantic tropical cyclone activity. Bull. Amer. Meteor. Soc., 85, 353-365.

Dunion, J. P., and C. S. Marron, 2008: A reexamination of the Jordan mean tropical sounding based on awareness of the Saharan air layer: Results from 2002. J. Climate, 21, 5242-5253.

Ek, M. B., K. E. Mitchell, Y. Lin, E. Rogers, P. Grunmann, V. Koren, G. Gayno, and J. D. Tarpley, 2003: Implementation of Noah land surface model advances in the National Centers for Environmental Prediction operational mesoscale Eta model. $J$. Geophys. Res., 108(D22), 8851, doi:10.1029/2002JD003296,.

Evan, A. T., J. P. Dunion, J. A. Foley, A. K. Heidinger, and C. S. Velden, 2006: New evidence for a relationship between Atlantic tropical cyclone activity and African dust outbreaks. J. Geophys. Res.,33, L19813, doi:10.1029/2006GL026408.

Evan, A. T., and Coauthors, 2008: Ocean temperature forcing by aerosols across the Atlantic tropical cyclone development region. Geochem. Geophys. Geosyst.,9, Q05V04, doi:10.1029/2007GC001774.

Gaffard, C, J. Nah, N. Atkinson, A. Bennett, G. Callaghan, E. Hibbett, P. Taylor, M. Turp, W. Schulz, 2008: Observing lightning around the globe from the surface. $20^{\text {th }}$ international lightning Detection conference.

Gallina, G.M., 2002: Environmental vertical wind shear and tropical cyclone intensity change utilizing enhanced satellite wind information. M.S. Thesis, University of Wisconsin-Madison, WI 53706133 pp.

Ginoux, P., M. Chin, I. Tegen, J. N. Prospero, B. Holben, O. Dubovik, and S. J. Lin, 2001: Sources and distributions of dust aerosols simulated with the GOCART model. Journal of Geophysical Research D,106,17, 20255-20273. 
Grell, G. A., S. E. Peckham, R. Schmitz, S. A. McKeen, G. Frost, W. C. Skamarock, and B. Eder, 2005: Fully coupled "online" chemistry within the WRF model. Atmospheric Environment, 39, 37, 6957-6975.

Hong, S. Y., J. Dudhia, and S. H. Chen, 2004: A Revised Approach to Ice Microphysical Processes for the Bulk Parameterization of Clouds and Precipitation. Mon. Wea. Rev., 132, 103-120.

Hong, S. Y., Y. Noh, and J. Dudhia, 2006: A New Vertical Diffusion Package with an Explicit Treatment of Entrainment Processes. Mon. Wea. Rev., 134, 2318-2341.

Jenkins, G. S., and A. Pratt, 2008: Saharan dust, lightning and tropical cyclones in the eastern tropical Atlantic during NAMMA-06. Geophys. Res. Lett., 35, L12804, doi:10.1029/2008GL033979.

Jenkins, G. S., A. Pratt, and A. Heymsfield, 2008: Possible linkages between Saharan dust and tropical cyclone rain band invigoration in the eastern Atlantic during NAMMA-06. Geophys. Res. Lett., 35, L08815, doi:10.1029/2008GL034072.

Karyampudi, V. M., and T. N. Carlson, 1988: Analysis and numerical simulations of the Saharan air layer and its effects on easterly wave disturbances. J. Atmos. Sci., 45, 3102-3136.

Karyampudi, V. M. and H. F. Pierce, 2002: Synoptic-scale influence of the Saharan air layer on tropical cyclogenesis over the eastern Atlantic. Mon. Wea. Rev., 130, 31003128.

Khain, A., D. Rosenfeld, and A. Pokrovsky, 2005: Aerosol impact on the dynamics and microphysics of deep convective clouds. Quart. J. Roy. Meteor. Soc., 131, 26392663.

Kumar, R., M. C. Barth, G. G. Pfister, M. Naja, and G. P Brasseur, 2013: WRF-Chem simulations of a typical pre-monsoon dust storm in northern India: influences on aerosol optical properties and radiation budget. Atmos. Chem. Phys. Discuss., 13, 21837-21881, doi:10.5194/acpd-13-21837-2013.

Lau, W. K. M., and K. M. Kim, 2007a: Cooling of the Atlantic by Saharan dust. Geophys. Res. Lett.,34, L23811, doi:10.1029/2007GL031538.

Lau, W. K. M., and K. M. Kim, 2007b: How nature foiled the 2006 hurricane forecasts. Eos. Trans. Amer. Geophys. Union, 88, doi:10.1029/2007EO090002. 
Lau, W. K. M., and K. M. Kim, 2007c: Reply to comment on "How nature foiled the 2006 hurricane forecasts." Eos. Trans. Amer. Geophys. Union, 88, doi:10.1029/2007EO260010.

Lee, A. C. L., 1990: Bias Elimination and Scatter in Lightning Location by the VLF Arrival Time DifferenceTechnique, Journal of Atmospheric and Oceanic Technology, 7 (5) 719-733.

Mlawer, E. J., S.J. Taubman, P. D. Brown, M. J. Iacono, and S. A. Clough, 1997: Radiative Transfer for Inhomogeneous Atmospheres: RRTM, a Validated Correlatedk Model for the Longwave. J.Geophys. Res., 102, 16 663-16 682.

Prospero, J. M., and T. N. Carlson, 1972: Vertical and areal distributions of Saharan dust over the western equatorial North Atlantic Ocean. J. Geophys. Res., 77, 5255-5265.

Prospero, J. M. and O. L. Mayol-Bracero, 2013: Understanding the transport and impact of African dust on the Caribbean basin. Bull. Amer. Meteor. Soc., 94(9), 1329-1337.

Reale, Oreste, K. M. Lau, Arlindo da Silva, 2011: Impact of Interactive Aerosol on the African

Easterly Jet in the NASA GEOS-5 Global Forecasting System. Wea. Forecasting, 26, 504-519.

Rosenfeld, D., Y. Ridich, and R. Lahav, 2001: Desert dust suppressing precipitation: A possible desertification feedback loop. Proc. Natl. Acad. Sci. USA, 98, 5975-5980.

Rhome, J. R., C. A. Sisko, and R. D. Knabb, 2006: On the calculation of vertical shear: An operational perspective. Preprints, 27th Conf. on Hurricanes and Tropical Meteorology, Monterey, CA, Amer. Meteor. Soc., 14A.4. [Available online at http://ams.confex.com/ams/pdfpapers/108724.pdf.].

Sippel, Jason A., Scott A. Braun, Chung-Lin Shie, 2011: Environmental Influences on the Strength of Tropical Storm Debby (2006). J. Atmos. Sci., 68, 2557-2581. doi: http://dx.doi.org/10.1175/2011JAS3648.1

Skamarock, W. C., J. B. Klemp, J. Dudhia, D.O. Gill, D. M. Barker, W. Wang, and J. G. Powers, 2008: A Description of the Advanced Research WRF Version 3. NCAR Tech. Note TN-475+STR. 125 pp.

Sun, D. L., K. M. Lau, M. Kafatos, Z. Boybeyi, G. Leptoukh, R. Yang, and C. Yang, 2009: Numerical simulations of the impacts of the Saharan Air Layer on Atlantic Tropical Cyclone Development. Journal of Climate, 22 (23), 6230-6250. 
Tao, W.-K., X. Li, A. Khain, T. Matsui, and S. Lang, 2007: Role of atmospheric aerosol concentration on deep convective pre- cipitation: Cloud-resolving model simulations. J. Geophys. Res., 112, D24S18, doi:10.1029/2007JD008728.

Twohy, C. H., and Coauthors, 2009: Saharan dust particles nucleate droplets in eastern Atlantic clouds. Geophys. Res. Lett., 36, L01807, doi:10.1029/2008GL035846.

Wong, S., A. E. Dessler, N.M. Mahowald, P. R. Colarco, and A. de Silva, 2008: Longterm variability in Saharan dust transport and its link to North Atlantic sea surface temperature. Geophys. Res. Lett., 35, L07812, doi:10.1029/2007GL032297.

Yuan, T., L. A. Remer, K. E. Pickering, and H. Yu, 2011: Observational evidence of aerosol enhancement of lightning activity and convective invigoration. Geophys. Res. Lett., 38, L04701, doi:10.1029/2010GL046052

Zhang, H., G. M. McFarquhar, S. M. Saleeby, and W. R. Cotton, 2007: Impacts of Saharan dust as CCN on the evolution of an idealized tropical cyclone. Geophys. Res. Lett., 34, L14812, doi:10.1029/2007GL030225.

Zhao, C., S. Chen, L. R. Leung, Y. Qian, J. F. Kok, R. A. Zaveri, and J. Huang, 2013: Uncertainty in modeling dust mass balance and radiative forcing from size parameterization. Atmos. Chem. Phys., 13, 10733-10753, doi:10.5194/acp-13-107332013.

Zipser, E. J., and Coauthors, 2009: The Saharan air layer and the fate of the African easterly waves-NASA's AMMA field study of tropical cyclogenesis. Bull. Amer. Meteor. Soc., 90, 1137-1156. 


\section{APPENDIX A}

\section{Acronyms}

AEJ $=$ African Easterly Jet

$\mathrm{AEW}=$ African Easterly Wave

AMMA $=$ African Monsoon Multidisciplinary Analyses

AOD $=$ Aerosol Optical Depth

$\mathrm{ASDC}=$ Atmospheric Science Data Center

$\mathrm{ATD}=$ Arrival Time Difference

CALIPSO $=$ Cloud-Aerosol Lidar and Infrared Pathfinder Satellite Observations

$\mathrm{CCN}=$ Cloud Condensation Nuclei

$\mathrm{dBZ}=$ Decibels of $\mathrm{Z}$

GFS $=$ Global Forecast System

GOCART $=$ Goddard Chemistry Aerosol Radiation Transport

GOES $=$ Geostationary Operational Environmental Satellites

GRIP $=$ NASA Genesis and Rapid Intensification Processes

IFEX $=$ Intensity Forecasting Experiment

MODIS = Moderate Resolution Imaging Spectroradiometer

MOVAS $=$ MODIS Online Visualization and Analysis System

MCS $=$ Mesoscale Convective System

NAMMA $=$ NASA African Monsoon Multidisciplinary Analyses

NASA $=$ National Aeronautics and Space Administration

NCEP $=$ National Centers for Environmental Prediction 
$\mathrm{NHC}=$ National Hurricane Center

NOAA $=$ National Oceanic and Atmospheric Administration

$\mathrm{NSF}=$ National Science Foundation

PREDICT $=$ Pre-Depression Investigation of Cloud-systems in the Tropics

$\mathrm{PW}=$ Precipitable Water

RH $=$ Relative Humidity

$\mathrm{SAL}=$ Saharan Air Layer

$\mathrm{SST}=$ Sea Surface Temperature

TC-genesis $=$ Tropical Cyclogenesis

$\mathrm{TD}=$ Tropical Depression

WPS $=$ WRF Pre-Processing System

$\mathrm{WRF}=$ Weather Research and Forecasting

$\mathrm{WRF}-\mathrm{ARW}=$ Advanced Research WRF

WRF-CHEM = WRF Chemistry model 